\title{
The Effect of Benefit Underreporting on Estimates of Poverty in the United States
}

\author{
Zachary Parolin ${ }^{1}$ \\ University of Antwerp
}
Pre-print of paper accepted for publication at Social Indicators Research (https://doi.org/10.1007/s11205-018-02053-0)

\begin{abstract}
The household income data used most frequently to estimate poverty rates in the United States substantially underreports the value of means-tested transfers. This paper investigates how underreporting affects estimates of the incidence and composition of poverty in the U.S. from 2013 to 2015. Specifically, I apply benefit adjustments for the underreporting of three social transfers to the Current Population Survey (CPS ASEC) to provide more accurate estimates of poverty rates. Diagnostic checks indicate that the imputed benefit adjustments are imperfect, but do provide a more accurate representation of household income than the uncorrected CPS ASEC data. In 2015, the benefit adjustments add more than $\$ 30$ billion of income transfers to the CPS ASEC, primarily concentrated among low-income households with children. I test the effects of the benefit corrections on two conceptualizations of poverty: the U.S. Supplemental Poverty Measure (SPM) and a relative measure of poverty set at 50 percent of federal median income. In 2015, the SPM poverty rate for the total population falls from 14.3 to 12.7 percent, a 1.6 percentage point (11 percent) decline, after adjusting for underreporting. Among children, the SPM poverty rate falls from 16.1 to 12.8 percent, a 3.3 percentage point (20 percent) decline. The percent-of-median poverty rate experiences similar declines after applying the benefit imputations. The findings suggest that the unadjusted CPS ASEC data meaningfully overestimates the incidence of poverty in the U.S., particularly among households with children. Documentation for applying the benefit corrections to the CPS ASEC is provided for improved estimates in future poverty research.
\end{abstract}

Keywords: poverty, income, CPS ASEC, measurement, child poverty

\footnotetext{
${ }^{1}$ Email: Zachary.Parolin@ uantwerpen.be. For providing helpful comments and suggestions, I am grateful to Bea Cantillon, Brian Nolan, Wim Van Lancker, Steven Pressman, Joyce Morton, Minna Nurminen, Jane Waldfogel, Chris Wimer, Michael Wiseman, and participants of the 2017 LIS User Conference. Any errors are my own.
} 


\section{INTRODUCTION}

Estimates of poverty play an important role in influencing social policy discourse. Comparisons of income-based poverty rates across time, region, and demographic group have been central to conclusions regarding the relative inclusiveness of nation-states (Atkinson 1998; Rainwater and Smeeding 2003), the efficacy of social transfers (Bitler et al. 2017; Meyer and Wu 2018), and the role of demographic features, such as family structure, in shaping life opportunities (Haskins and Sawhill 2009). This paper demonstrates, however, that estimates of poverty in the United States are often derived from a data source that suffers greatly from the underreporting of means-tested social transfers. I show that addressing the issue of benefit underreporting not only leads to notable declines in estimates of poverty in the U.S., but also affects understandings of the demographic features of individuals living in poverty.

Benefit underreporting in U.S. survey data is not a new concern. As far back as 1992, the U.S. Census Bureau acknowledged that, due to underreporting, as much as 20 percent of cash transfers were unmeasured in household income data (U.S. Census Bureau 1992). The extent of underreporting in the Current Population Survey Annual Social and Economic Supplement (CPS ASEC) - the source of data most often used to produce estimates of U.S. poverty - appears to have worsened over time (Wheaton 2008). Recently, studies have found that nearly 50 percent of certain social transfers are unmeasured in the CPS ASEC (Meyer et al. 2009; Meyer and Mittag 2015). Despite ample evidence of benefit underreporting, however, few scholars have utilized publicly-available resources for addressing the issue.

This paper applies adjustments for the underreporting of three social transfers to the CPS ASEC from 2013 to 2015 to produce improved estimates of poverty. Specifically, I address the underreporting of the Supplemental Nutrition Assistance Program (SNAP, often referred to as food stamps), Temporary Assistance for Needy Families (TANF, a state-run social assistance program), and Supplemental Security Income (SSI, a means-tested income supplement targeted 
at blind, disabled, and/or older-age adults). Combined, these three programs accounted for more than $\$ 130$ billion in cash or near-cash transfers in 2015 . As this paper will document, however, more than a third of this sum (around $\$ 45.6$ billion) is unmeasured in the CPS ASEC, leading to an underestimation of household incomes toward the bottom of the income distribution.

Recent studies have made important progress in integrating administrative records into household surveys to address the issue of underreporting (Meyer and Wu 2018; Fox et al. 2017). The integration of administrative data should be considered the "gold standard" in improving the reliability of household income data. However, important limitations exist in current capabilities to produce national poverty estimates using the integrated data. Most importantly, administrative records for programs such as SNAP and TANF are only available for a subset of states (as few as 12 states for SNAP in Meyer and Wu (2018)). This paper instead applies an intermediate method to adjust for benefit underreporting: probability-based benefit imputations that improve the accuracy of SNAP, TANF, and SSI benefits across all states (rather than a select few) over the most recent years of household income data.

Specifically, I apply the Urban Institute's Transfer Income Model, Version 3 (TRIM3) model to impute improved estimates of household benefit receipt back into the CPS ASEC. After performing several diagnostic checks at the national and state levels, I find that TRIM3 adjustments for benefit underreporting perform much better than the unadjusted CPS ASEC in matching administrative records on benefit dispersal. I then apply the adjusted income data to re-estimate the incidence of poverty in the U.S. in 2015. Acknowledging the conceptual debates in poverty measurement literature, I demonstrate the effect of the TRIM3-adjusted benefit adjustments on two measures of income-based poverty: the U.S. Supplemental Poverty Measure (SPM) and a relative measure that sets the poverty line at 50 percent of national equivalized household median income. While the SPM is used frequently in U.S. poverty 
literature, the percent-of-median concept is applied regularly in cross-national research and is used to compare levels of poverty in the U.S. to that of other wealthy nations.

The findings lead to three primary contributions to social policy and poverty literatures. First, I show that underreporting leads to substantial overestimations of the incidence of poverty in the United States. After applying the TRIM3 benefit adjustments, the estimated SPM poverty rate for the total population in 2015 falls from 14.3 to 12.7 percent, a 1.6 percentage point (11 percent) decline. The estimated percent-of-median poverty rates falls from 16 to 14.8 percent, a 1.2 percentage point ( 8 percent) decline.

Second, I demonstrate that the improved data might also affect understandings of who lives in poverty. Specifically, the findings suggest that the unadjusted CPS ASEC is likely to overestimate poverty rates for households with children. For the SPM, poverty among children in single-parent households declines from 27.8 to 21.8 percent, a 6 percentage point (22 percent) change after adjusting for underreporting in TANF, SNAP, and SSI. Thus, use of the unadjusted data may bias conclusions regarding the relationship between family structure and the likelihood of poverty in the U.S.

In addition to demonstrating the effect of benefit underreporting on the incidence and composition of poverty, this paper also hopes to enable further evaluation of the benefit imputations and more accurate poverty research in the future. Though TRIM3 brings a substantial share of social transfers back into the CPS ASEC, evidence suggests that it may over-allocate its added benefits toward the bottom of the income distribution (Stevens et al. 2018). The benefit imputations increase the number of 'true positives' (individuals receiving benefits in the survey data and in reality), but at the cost of also increasing the number of false positives (receiving benefits in the survey data but not in reality). I discuss the implications of these findings and conclude that TRIM3, though an improvement over the unadjusted CPS ASEC, should be understood as an imperfect fix for the issue of benefit underreporting. To 
promote further evaluation of the benefit imputations, this paper's third primary contribution comes in the documentation provided for future researchers to apply the TRIM3 imputations to the CPS ASEC. Following the guide presented in the Appendix, researchers can utilize the TRIM3 imputations to continue evaluating the veracity of the benefit adjustments and to generate more accurate estimates of poverty in future research.

\section{BACKGROUND}

\section{MEASUREMENT ERROR IN HOUSEHOLD INCOME DATA}

Survey data that require respondents to recall information from their past, or to share potentially sensitive information, are inevitably susceptible to measurement concerns (Bound et al. 2001). With respect to income surveys, evidence suggests that two measurement concerns - missing data and measurement error - are particularly consequential in producing accurate assessments of household income (Nicoletti et al. 2011). Missing data issues occur when respondents refuse to answer certain questions in the survey, or when they refuse to submit their survey questionnaire altogether. Conversely, measurement error results when respondents misreport the true value of certain income components. As Kasprzyk (2005) describes, measurement error can be thought of as the difference between the value of a characteristic that the respondent provides and the 'true' value of that characteristic. In the case of income statistics, reported income values are often compared to independent benchmarks, such as administrative records, to estimate the extent of measurement error within the survey data (Moore et al. 2000).

This paper focuses primarily on measurement error within the CPS ASEC. The CPS ASEC is the source of data used to produce official U.S. poverty estimates. It also serves as the input data for the Organisation for Economic Co-operation and Development (OECD) and for LIS, the Cross-National Data Center in Luxembourg, from which estimates of U.S. poverty 
rates are often derived for the purpose of cross-national research. Among nationallyrepresentative surveys of American households' financial details, the CPS ASEC provides the most detailed information regarding income, transfers, and taxes.

The source of measurement error that this paper focuses on is the substantial underreporting of transfer income within the CPS ASEC. The underreporting of means-tested transfers inhibits the CPS ASEC from producing accurate estimates of disposable income among households toward the bottom of the income distribution (Meyer et al. 2009; Meyer and Mittag 2015; Wheaton 2008). Plotting the CPS ASEC data against administrative records, for example, Meyer and Mittag (2015) find that the survey data underestimates the quantity of housing assistance recipients in New York by more than 33 percent, SNAP recipients by more than 40 percent, and TANF recipients by more than 60 percent. Similarly, Wheaton (2008) finds that the proportion of real TANF, SNAP, and SSI caseloads captured in the CPS ASEC declined relative to the values reported in administrative data between 1993 and 2005. In 1993, about 74 percent of TANF benefits and 67 percent of SNAP benefits were measured in the data; by 2005, this had fallen to 59 percent of TANF benefits and 57 percent of SNAP benefits.

This paper will focus exclusively on estimating the consequences of benefit underreporting for estimates of poverty within the CPS ASEC. Importantly, however, issues of measurement error are not unique to American survey data. Mismatches between survey data and administrative records have been identified among earnings data in Denmark (Kristensen and Westergard-Nielsen 2006), earnings and pensions in Sweden (Kapteyn et al. 2007), total household income in France, and transfer income in Italy, to name a few examples (Jäntti et al. 2013). Increasingly, however, Member States of the European Union (EU) are moving toward the integration of register data into the EU Statistics on Income and Living Conditions (EUSILC), the primary source of household income data for EU Member States. The Nordic countries, Ireland, the Netherlands, Slovenia, and Switzerland, for example, each collect 
income data primarily from administrative records (Jäntti et al. 2013). Ten other EU Member States use a mix of survey and administrative collection when producing income data. Though the increased use of administrative records cannot rid concerns of measurement error (and administrative data itself cannot be assumed to be perfect), the practice nonetheless marks an improvement over a pure reliance on survey responses for producing income statistics.

In contrast, earnings and transfer income within the CPS ASEC are self-reported. As such, the probability of measurement error for any given income item is likely higher than if administrative data were used to report the value of the income item. Indeed, the evidence of substantial underreporting of means-tested transfers within the U.S. data suggests that this is the case. This paper focuses on measurement error exclusively in SNAP, TANF, and SSI for several reasons. First, they are each means-tested social transfers that prior literature has established as likely to be underreported in survey data. Second, the three programs are particularly likely to affect poverty rates, given that they tend to be underreported and are targeted at lower-income households. Third, and more pragmatically, these are the three social transfer programs for which imputation-based benefit adjustments are consistently available over time. The sources of measurement error may vary across these programs. While SNAP, TANF, and SSI may experience reporting errors due to recall issues or stigmatization of benefit receipt, Bee and Mitchell (2017) suggest that one source of error for SSI, specifically is confusion around program names. ${ }^{2}$ Specifically, the authors find that survey respondents often confuse the SSI program with that of the Social Security Disability Insurance (SSDI) program,

\footnotetext{
${ }^{2}$ Each year, some survey respondents do not answer the survey questions on the value of social program programs (item nonresponse). The Census Bureau allocates participation and benefit values to households that do not provide a response, but are estimated to be participating in the given benefit (Wheaton \& Tran, 2018). Thus, what starts as a 'missing data' issue becomes a potential source of measurement error (if the imputed values are different from the true values) in the version of the CPS ASEC made public. The large majority of survey respondents, however, do provide answers to all social transfer questions (Kasprzyk, 2005).
} 
a non-means-tested social insurance program targeted at individuals who are physically restricted in their ability to seek employment. ${ }^{3}$

Importantly, underreporting does not appear to be due to systematic under-coverage or sampling frame issues. The Census Bureau's weighting procedures account for potential undercoverage or undercount of individuals based on age, race, sex, and Hispanic origin (Wheaton 2008). Moreover, measurement error in reported benefits does not appear to be due to systematic bias in survey response rates among lower-income households (Bee et al. 2015). Indeed, the Survey of Income \& Program Participation (SIPP) also undercounts SNAP, TANF, and SSI benefits despite its oversampling of low-income households, suggesting that the existence of benefit underreporting is not merely a product of sampling frame (Mittag 2016; Wheaton 2008).

Social transfers are one of several components of survey-based income data that are prone to measurement error. Evidence suggests, for example, that measurement issues also occur at the very top of the income distribution, due a combination of survey under-coverage of high incomes, survey top-coding of very high incomes, and misreporting of assets, dividends, and other financial gains (Burkhauser et al. 2018) This is often true even when integrating administrative records. As these issues do not generally affect estimates of poverty, as this paper focuses on, I do not discuss them in greater detail. There is also some evidence of earnings underreporting, particularly among part-time, informal, or seasonally-employed workers. While these concerns are likely to affect estimates of poverty, they cannot generally be resolved

\footnotetext{
${ }^{3}$ If a survey respondent mistakenly reported SSI benefits as SSDI benefits, it is possible that adjusting for the underreporting of SSI while not adjusting SSDI benefits may double count the income source. This would, in turn, affect the TRIM3-adjusted poverty estimates presented in this paper. To account for that possibility, I present revised poverty estimates disaggregated by program in Appendix III type to clarify how TRIM3 would affect poverty rates even if the SSI adjustments were to be excluded. I thank an anonymous reviewer for bringing this to my attention.
} 
in the same manner as social transfers (through probability-based benefit imputations) (Weinberg 2004; Bound and Krueger 1991; Rodgers et al. 1993).

Several studies have made initial progress toward addressing the issue of benefit underreporting. Of particular importance is the work of Bruce Meyer and colleagues (Meyer and Wu 2018; Meyer et al. 2009), who have worked to link administrative records on benefit receipt to the SIPP. The integration of administrative records into household income surveys is certainly superior to probability-based imputation techniques, as applied in this paper. That said, several important shortcomings exist with respect to the current capabilities of linked administrative-survey data. Most consequential is that state agencies are not required to provide the information necessary to link their records to survey data, and many do not. Meyer $\& \mathrm{Wu}$ (2018), for example, apply SNAP administrative records for only 12 states and TANF data for 30 states. As such, the authors can use the improved SIPP data to re-estimate the impact of social transfers on household income within those 12 states, but cannot re-estimate levels of poverty across the U.S. Moreover, the U.S. Census Bureau recommends use of the CPS ASEC to SIPP when producing cross-sectional estimates of poverty, in part due to its broader set of household income information and increased sample size (Bishaw 2017). As detailed before, the CPS ASEC is the data source used to produce official poverty estimates, including the SPM.

Using the CPS ASEC, Fox et al. (2017) have utilized administrative data on SNAP records to overcome concerns of SNAP underreporting, but again in only a select number of states. Similarly, Meyer and Mittag (2015) used linked administrative data for the state of New York to assess the effects of underreporting within the state. Winship (2016) has applied TRIM3 adjustments to the CPS ASEC, similar to this paper, to challenge prior estimates of the incidence of deep or 'extreme' poverty. To my knowledge, however, no study has applied benefit adjustments for SNAP, SSI, and TANF across each of the 50 states for the purpose of evaluating the two poverty concepts most utilized in recent social policy literature: the SPM 
and relative (percent-of-median) measures. I emphasize three reasons why an investigation into the effects of underreporting on poverty is necessary.

The first is straightforward: estimates of poverty provide an important benchmark of economic wellbeing and social inclusiveness. Changes in poverty rates over time provide signals as to the relative health of the economy and the relative wellbeing of the nation's households (Rainwater and Smeeding 2003). Given this, it is particularly problematic if underreporting of transfer benefits increases over time which, as Wheaton (2008) suggests, is indeed the case. Thus, ostensible increases in poverty within the U.S. may simply reflect an increase in benefit underreporting. From a cross-national perspective, poverty rates across wealthy nations are often interpreted as an indicator of social inclusion and used to drive social policy recommendations (Cantillon and Vandenbroucke 2014).

This leads to a second point: biases in the measurement of poverty (and household income, more generally) affect understandings of the efficacy of social transfers. Policy analysis research often aims to decompose the effect of policy changes on household incomes. For example, researchers might ask how the expansion of certain social programs, such as SNAP, affect the economic wellbeing of households with children (Keith-Jennings 2012; Fox et al. 2017). If the survey data fail to accurately capture the real value of benefits distributed, however, then the analyses may likewise be biased. In their application of SNAP and TANF administrative data to the SIPP across 12 states, for example, Meyer and Wu (2018) find that the transfer programs are far more effective than the unadjusted survey data would claim.

Finally, underreporting is relevant in that its effects are not neutral across demographic groups. Consider that TANF and SNAP benefits, in particular, are concentrated among lowincome households with children (and single mothers, in particular). Thus, underreporting of these two benefits may disproportionally affect poverty rates among single parents, or households with children in general. In other words, poverty estimates derived from the 
unadjusted CPS ASEC may lead to overstated conclusions regarding the strength of the relationship between family structure and the likelihood of poverty.

\section{MEASURING POVERTY}

Poverty measurement is a contested field. Scholars have proposed conceptualizations of poverty that take into account household consumption (Meyer and Sullivan 2006), material deprivation (Nolan and Whelan 2011), individual preferences (Decancq et al. 2015), and more. This paper, however, focuses exclusively on income poverty. Specifically, I investigate what are perhaps the two most commonly utilized measures to estimate the rate of poverty in the U.S.: the SPM and a relative measure of poverty set at 50 percent of national median household income. The SPM is used exclusively in U.S.-centric research, while the percent-of-median measure is applied regularly in cross-national research (Fox et al. 2014; Brady and Destro 2014). The purpose of this paper is not to debate the relative merits of either approach; conceptual disputes regarding relative, quasi-relative, and absolute poverty measures are neatly summarized in Corak (2005); Brady and Destro (2014); and Foster (1998). Given that both the SPM and percent-of-median measures are used frequently in poverty research, clarifying how benefit underreporting in the CPS ASEC affects estimates of each is relevant for improving the quality of future poverty analyses. I now describe the primary features of the two poverty measures in turn.

The SPM was introduced in 2011 to supplement the 'Official Poverty Measure' (OPM) in the U.S. Different from the OPM, the SPM poverty threshold is based on geographic differences in housing costs and a five-year moving average of mean expenditures on food, clothing, shelter, and utilities (Fox and Renwick 2016). Moreover, the SPM takes into account all government transfers (such as SNAP benefits, in contrast to the OPM) and taxes (including refundable tax credits) when measuring household income. This comprehensive definition of household income is similar to the income definition used in cross-national research, including 
the percent-of-median approach discussed next. One key difference with the SPM, however, is that work expenses, out-of-pocket medical expenses, and child support paid to another household are deducted from household income before determining the household's poverty status. Rather than measuring income and poverty status at the family level (like the OPM) or the household level (as percent-of-median measures often do), the SPM unit of analysis falls in between. Formally, the units are referred to as "SPM units," which take into account more complex household and family arrangements, such as non-related cohabitating adults, unmarried parents of children in the household, foster children, or non-related children living within the household (Provencher 2011). During 2013-2015, around 3.9 percent of households contained more than SPM unit. In 2015, the SPM poverty rate was 14.3 percent for the total population and 16.1 percent for children, before adjusting for benefit underreporting.

The 'relative' measure of poverty is the concept utilized in most EU and OECD Member States. It is particularly common in cross-national comparisons of poverty (Corak 2005; Brady and Destro 2014; Gornick and Jäntti 2012). Relative poverty thresholds are generally drawn at 50 percent of median equivalized household income (though variations, such as 40 or 60 percent, are also common). Proponents of the percent-of-median approach argue that thresholds based on median incomes appropriately adjust to the relativity of living standards across place and time (Chen and Corak 2005; Brady 2009). Though some reference group theorists might argue that poverty thresholds should be drawn for each state in the U.S. (set at 50 percent of each state's respective median income), I stick to a common national-level threshold for practical purposes: this is the approach that the OECD, LIS, and others adopt and apply most frequently in cross-national research. I also apply the LIS definition of disposable household income, which incorporates all taxes and transfers when calculating a household's net income. The household, rather than SPM unit, is the unit of analysis of the percent-of-median measures. 
Before adjusting for benefit underreporting, the percent-of-median poverty rate was 16 percent for the total U.S. population in 2015 and 19.2 percent among children.

\section{DATA \& METHODS}

The methodological approach, as well as the presentation of the findings, proceeds in four stages. I first document the extent of benefit underreporting in the unadjusted CPS ASEC from 2013 to 2015. Second, I apply adjustments for the underreporting of TANF, SNAP, and SSI programs. Third, I perform diagnostic checks to assess the reliability of the benefit adjustments. Finally, I re-estimate poverty rates using the adjusted version of the CPS ASEC.

\section{Benefit Underreporting}

Receipt of TANF and SSI benefits is reported at the individual level in the CPS ASEC, while SNAP benefits are reported at the household level. ${ }^{4}$ To document the level of benefit underreporting in the CPS ASEC, I aggregate benefit levels at the household level and use household weights to compute the weighted annual sums of reported SNAP, TANF, and SSI transfers in the survey data. I then compare the annual sums to administrative records on actual benefit allocations. This approach is similar to that of Meyer et al. (2009), Mittag (2016), and Wheaton (2008). This practice does have its limitations: as individuals who are homeless or living in institutions are not included in the CPS ASEC sample, their receipt of transfer benefits could affect the mismatch between the aggregated totals found in the survey data versus the totals described in administrative records. However, consider that the homeless point-in-time count estimated about 550,000 homeless individuals living in the U.S. in 2015, whereas more than 40 million people lived in households receiving SNAP benefits in 2015 (Henry et al. 2015).

\footnotetext{
${ }^{4}$ I use the "source of welfare income" variable in the CPS ASEC to separate TANF benefits from other public assistance programs, such as state-provided General Assistance. When a respondent indicates that the source of his/her welfare income is both TANF and non-TANF assistance, I opt to include the total value in my calculation of TANF benefits. As the number of such cases is small ( 0.01 percent of respondents), removing the combined value from TANF calculations makes no substantive difference to the findings presented here.
} 
Thus, even if all homeless individuals received transfers benefits (very improbable), this would have a small relative effect on the overall size of the programs.

According to the U.S. Department of Agriculture (2017), more than \$69.6 billion in SNAP benefits were distributed in 2015 . In the same year, approximately $\$ 56.2$ billion in SSI benefits were distributed, and approximately $\$ 7.7$ billion in cash assistance from TANF (Social Security Administration 2017; Office of Family Assistance 2015). I use these sources throughout this paper when comparing CPS ASEC data to administrative records.

\section{Imputing Benefit Adjustments}

After documenting the extent of underreporting, I utilize the Urban Institute's TRIM3 model to impute a large share of the unmeasured SNAP, SSI, and TANF benefits back into the CPS ASEC (Zedlewski and Giannarelli 2015). ${ }^{5}$ In short, TRIM3 utilizes information about each individual and household in the CPS ASEC to predict their likelihood of benefit receipt, as well as the value of benefits that a recipient is likely to receive. The simulations take into account program participation and benefit allocation data from federal and state administrative records when assessing the likelihood that a given household within the CPS should be assigned benefits. Thus, the simulation process is able to take into account individual/household data on race, ethnicity, immigrant status, marital status, household structure, state of residence, income, state-level policy rules, and more to estimate program participation and benefit levels. The simulated SNAP, SSI, and TANF benefit levels can be used in place of reported values to adjust for under-reporting within the CPS ASEC.

\footnotetext{
${ }^{5}$ TRIM3 creates replicates of immigrant households in its simulations to account for uncertainty in 'undocumented status' versus 'legal permanent resident status' when allocating transfer benefits. In utilizing the TRIM3-adjusted survey data, researchers can choose to either keep the replicate households and use a TRIM3provided weight, or to re-aggregate the cloned households back into a single household, in which case the CPSprovided weights can be utilized. As detailed in the replication dofiles in Appendix IV, I convert the cloned households back into their original households. I follow TRIM3 guidelines in utilizing the replication weights to aggregate the TRIM3-adjusted benefits back to the original household level.
} 
A full description of the simulation methodology is detailed in Zedlewski and Giannarelli (2015). Here, I highlight the three primary steps of the imputation procedure, using SNAP as an example. In the Supplemental Appendix, I provide more extensive documentation on the imputations. Step one identifies the units eligible to receive SNAP benefits. As Wheaton and Tran (2018) summarize, TRIM3 "follows the same steps as would be followed by a caseworker, such as applying rules for noncitizens' and students' eligibility, applying the liquid assets (resource) test, computing gross income, calculating deductions to determine net income, and performing the income tests." Eligibility is determined on a monthly basis and takes into account state-level variation in eligibility rules, broad-based categorical eligibility policies, and state waivers for participation among able-bodied working-age adults.

The second stage then calculates the potential benefit value of the eligible units. Monthly benefit values are assigned based on program rules and the size, characteristics, and income of the SNAP unit (most often the household). The third stage then predicts benefit participation among eligible units. If a unit in the CPS ASEC is eligible for SNAP benefits and reports receiving SNAP benefits, then the TRIM3 model includes it in its participation count. Among units that are eligible but do not report benefit receipt, TRIM3 simulates participation to meet administrative targets on household type (single-parent household, two-parent household, number of individuals aged 60+), benefit receipt of TANF and SSI, benefit levels (increments of $\$ 1-\$ 50, \$ 51-100$, and so on), state of residence, and citizenship status. More specifically, TRIM3 produces an initial probability of participation based on the unit type (for example, single parent with two children) and the amount of benefits that the unit is eligible for (as units eligible for higher benefit values are likelier to participate). Probabilities are set so that the aggregate targets (administrative caseload numbers) of SNAP participation will be met. The probability that a unit participates in a benefit is then altered according to its state of residence and citizenship status of individuals in the households. Among units eligible to receive SNAP 
benefits, a random number generated for each unit is compared to the unit's participation probability, and those with random numbers below the probability threshold will participate. Units ineligible to receive SNAP benefits are excluded from the participation simulation. This procedure is presented in more detail within the Supplemental Appendix and in Zedlewski and Giannarelli (2015). Similar procedures are used to estimate SSI and TANF eligibility and benefit values, again taking into account benefit rules and regional variation in benefit levels and probability of participation.

\section{Assessing the Accuracy of the Benefit Imputations}

After using TRIM3 to impute the SNAP, SSI, and TANF benefits back into the CPS ASEC, I assess the accuracy of the benefit imputations relative to administrative records on benefit dispersal. To do this, I begin with a comparison of the weighted annual sum of transfers (now with the imputed benefits) to the administrative data. I also analyze the distribution of benefits by state to assess the geographic dispersion of imputed TRIM3 benefits. Due to a lack of accessible, state-level administrative data on the characteristics of households receiving transfer benefits, however, I am unable to assess whether the TRIM3-adjusted benefits are distributed accurately across household types and demographic features at the state level. ${ }^{6}$

Among the three transfer programs addressed here, SNAP features the most detailed records on the demographic composition of households participating in the program. Specifically, the SNAP quality control (QC) reports provide annual data on monthly samples of SNAP participants across the U.S. broken down by household size and family type. I use the SNAP QC report from 2015 as a benchmark to compare the characteristics of SNAP participants in the unadjusted and TRIM3-adjusted CPS ASEC. As surveys, the SNAP QC

\footnotetext{
${ }^{6}$ Access to administrative records on benefit dispersal that can be integrated into survey data are heavily restricted and not available for public use. Moreover, these records are generally available for only a small subset of states, as described before. Therefore, I am unable to compare the distribution of TRIM3 benefits directly to linked administrative-survey records.
} 
reports are also prone to measurement error; however, they are unique in that they target only households receiving SNAP benefits and, thus, provide a useful and representative portrait of the characteristics of SNAP recipients. The sample size of the SNAP QC in 2015 was 48,022.

Ideally, this validation exercise would be able to compare whether the TRIM3-adjusted benefits match administrative data with respect to the national income distribution of SNAP, TANF, and SSI recipients. National administrative data on benefit receipt and levels, however, do not report information on the income distribution of households receiving the benefit. The SNAP QC surveys share monthly income information for SNAP recipients, but this monthly data is not comparable to the annual income reported in the CPS ASEC. This is a potential concern. Investigating the accuracy (relative to administrative records) of TRIM3's SNAP adjustments for the New York State sample in 2010, for example, Mittag (2016) finds that the SNAP benefit adjustments improve the accuracy of participation rates and levels of benefits, but overcorrect among low-income households. Stevens et al. (2018) perform a similar analysis across seven states, finding that the unadjusted and TRIM3-adjusted CPS ASEC both overallocate SNAP participation to low-income households. Building on these findings, I also present the gross income distribution of benefit recipients before and after applying the TRIM3 adjustments. This provides an initial indication of the effect of TRIM3 imputations across the income distribution, and provides a foundation for further diagnostic checks as administrative records become more accessible and expand their coverage across a larger number of states.

\section{Re-estimating Poverty Rates}

Finally, I re-estimate U.S. poverty rates in 2015 using the adjusted SNAP, SSI, and TANF benefit levels. As detailed in the prior section, I compute poverty estimates using both the SPM and percent-of-median conceptualizations of poverty. In addition to providing improved estimates of poverty for the total population, I decompose poverty estimates by family structure to demonstrate the effects of the benefit adjustments on demographic differences in 
poverty rates. Researchers can replicate the poverty analyses presented here using the documentation and replication code provided in Appendix IV.

\section{FINDINGS}

Assessing the Reliability of the TRIM3 Benefit Adjustments

I first document the extent of benefit underreporting in the CPS ASEC from 2013 to 2015. Figure 1 shows that the pattern of underreporting for SNAP, TANF, and SSI is consistent across the three years. The unadjusted CPS ASEC captures an average of 53.2 percent of SNAP benefits over the three years. In 2015, this is equal to around $\$ 33$ billion of unmeasured SNAP benefits (47.4 percent of the $\$ 69.4$ billion in SNAP allocations unmeasured in 2015).

Underreporting is even more severe for the TANF program. Over the three years, an average of 47.6 percent of TANF cash assistance is measured in the CPS ASEC. In 2015, only 44.7 percent of the $\$ 7.7$ billion in cash assistance appears in the data, leaving roughly $\$ 4.2$ billion of unmeasured TANF benefits in 2015 .

The CPS ASEC appears to do a far better job of measuring SSI benefits. In each year, at least 80 percent of SSI benefits are captured in the data (a three-year mean of 84.8 percent). Because SSI is a substantially larger program relative to TANF, however, even 15 percent of benefits unaccounted for can lead to greater potential biases in the measurement of household income. In 2015, $\$ 56.2$ billion in SSI benefits were distributed, 85.2 percent of which are accounted for in the unadjusted data. The amount of unmeasured benefits is thus equal to around $\$ 8.3$ billion in 2015 .

The estimates in Figure 1 align with the patterns of benefit underreporting documented in prior evaluations (Meyer et al. 2009; Wheaton 2008). Aggregating the sums of the unmeasured benefits, we can estimate that about $\$ 45.5$ billion worth of SNAP, TANF, and SSI transfers are unaccounted for in the 2015 CPS ASEC. 


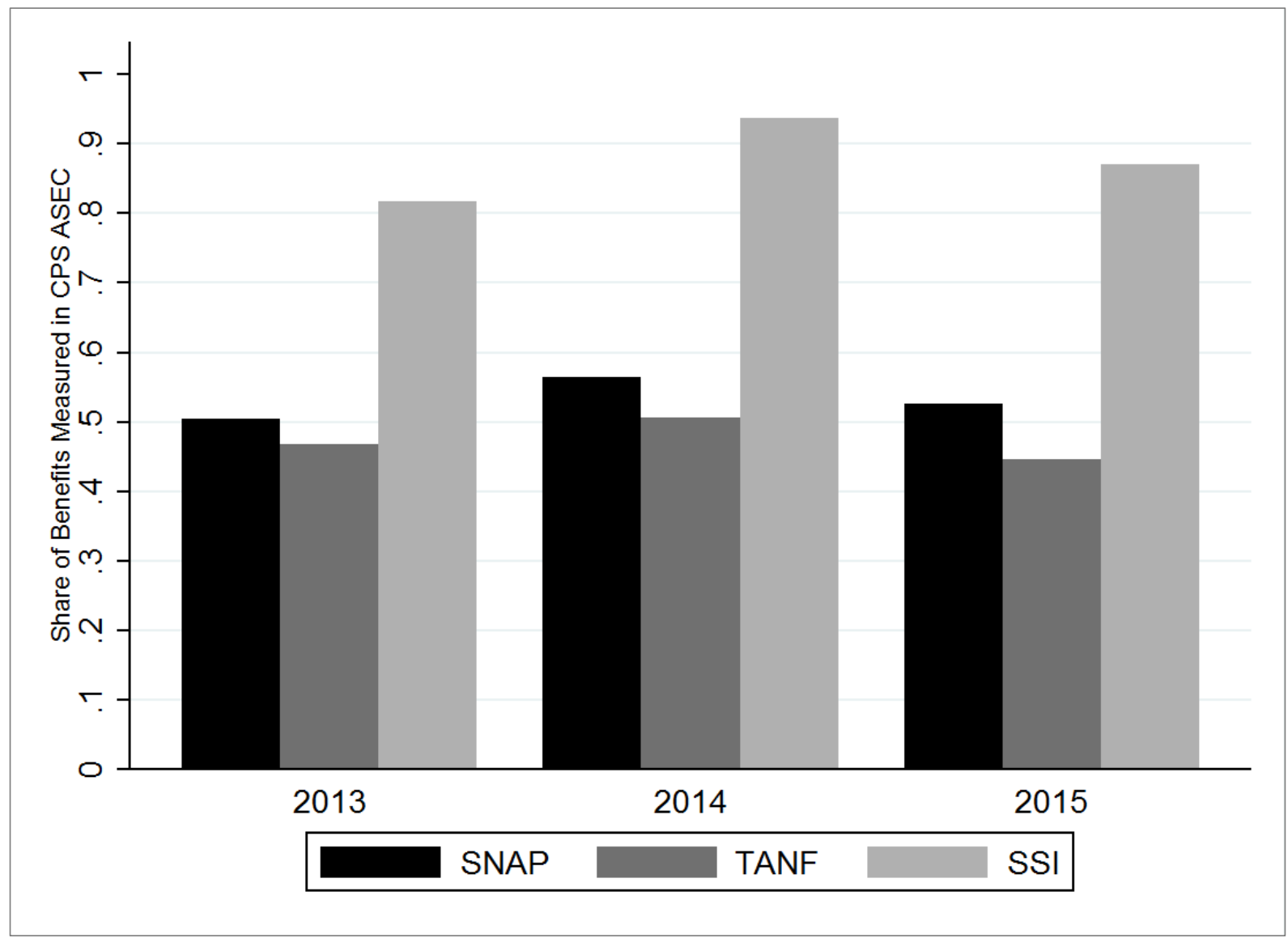

Note: Weighted annual sums of reported benefits in CPS ASEC are estimated at household level. Administrative data on SNAP, TANF, and SSI benefit allocations come from U.S. Department of Agriculture (2017); Office of Family Assistance (2015); and Social Security Administration (2017) respectively. Source of survey data: IPUMS-CPS database (Flood et al. 2018).

How do the imputed TRIM3 benefit adjustments compare to the administrative data? Table 1 presents the findings. The first row presents the total benefit allocations according to administrative records in 2015. The second and third rows show, respectively, the share of benefits captured in the unadjusted CPS ASEC versus the TRIM3-adjusted data. The fourth row then estimates the total value of SNAP, TANF, and SSI benefits added to the CPS ASEC with the TRIM3 adjustments. Though I present results here for 2015, findings for the years 2013 and 2014 are substantively similar. 
Table 1: Means-Tested Transfers in CPS ASEC Before \& After TRIM3 Imputations (2015)

\begin{tabular}{lccc}
\hline & SNAP & TANF & SSI \\
\hline $\begin{array}{l}\text { Total Benefit Allocation } \\
\text { (in millions) }\end{array}$ & $\$ 69,645$ & $\$ 7,700$ & $\$ 56,201$ \\
$\%$ Measured in CPS & $52.6 \%$ & $44.7 \%$ & $85.2 \%$ \\
$\%$ Measured w/ TRIM3 & $86.6 \%$ & $84.2 \%$ & $93.5 \%$ \\
\hline $\begin{array}{l}\text { Increase in Transfers w/ TRIM3 } \\
\text { (in millions) }\end{array}$ & $\$ 23,740$ & $\$ 3,042$ & $\$ 4,680$ \\
\hline
\end{tabular}

Note: Administrative data on SNAP, TANF, and SSI benefit allocations come from U.S. Department of Agriculture (2017); Office of Family Assistance (2015); and Social Security Administration (2017) respectively. Weighted benefit sums are estimated at the household level using household weights provided in the CPS ASEC.

As Table 1 shows, the TRIM3 benefit adjustments for SNAP, TANF, and SSI each come much closer to administrative records relative to the unadjusted CPS. The imputed SNAP benefits amount to 86.6 percent of the total value of SNAP benefits allocated in 2015 . This is a substantial improvement to the unadjusted CPS ASEC (which captures 52.6 percent of the total in this year) and leads to a sum of about $\$ 23.7$ billion added into the CPS ASEC.

Similar patterns exist with respect to TANF and SSI adjustments. For TANF, the TRIM3 adjustments add in more than $\$ 3$ billion in cash assistance. More than 84 percent of the total value is now accounted for, relative to the 44.7 percent in the unadjusted data. For SSI, 93.5 percent of the benefits are accounted for after the TRIM3 adjustments - an increase of nearly $\$ 4.7$ billion added to the CPS ASEC. In all, the TRIM3 adjustments add more than $\$ 30$ billion of transfers in 2015 alone and provide a more accurate representation of the total sum of benefits allocated. The inability of TRIM3 to measure the full 100 percent of the administrative totals reflects, first, that some individuals outside the CPS ASEC sampling frame (such as homeless or institutionalized individuals) also receive transfer benefits and, second, that measurement error still exists within the TRIM3 imputations. 
In Appendix I, I present a state-level analysis of SNAP, TANF, and SSI benefits measured in the CPS ASEC before and after adding the TRIM3 imputations. Following Census Bureau recommendations when analyzing state-level data, I combine three consecutive years of data (2013 to 2015) to increase sample sizes and reduce the potential for measurement error. This state-level analysis helps to assess the relative accuracy of the geographic distribution of TRIM3 imputations. For each of the three benefits, the TRIM3 imputations perform better than the unadjusted CPS in matching state administrative records on benefit allocations. For the average state, the unadjusted CPS ASEC was 44 percentage points off of administrative records in the sum of SNAP benefits measured. The TRIM3-adjusted data, conversely, was an average of 12.1 percentage points off. Similar patterns exist with respect to TANF and SSI benefits. However, the findings also show large inconsistencies across states in the share of benefits captured, both before and after applying TRIM3. Even after applying TRIM3, benefits appear to be over-counted (the levels in the survey data are larger than the levels in the administrative records) in roughly a fifth of states for each program. More research is needed into understanding the sources of this variation across states, and caution should urged when interpreting state-level results using either the unadjusted or TRIM3 data.

Table 2 compares participation rates and household composition of SNAP beneficiaries in the survey data to administrative records and SNAP quality control (QC) surveys in 2015. Again, the SNAP QC data is an annual summary of monthly surveys of SNAP beneficiaries. According to the SNAP administrative records, approximately 17.9 percent of households received SNAP benefits in 2015. The unadjusted CPS ASEC suggests that 11.1 percent of households received SNAP benefits, while the TRIM3-adjusted estimate of SNAP participation nears that of the administrative records (the difference between the administrative total and TRIM3 estimate is not statistically significant). 
Table 2: Characteristics of Households Receiving SNAP Benefits (2015)

\begin{tabular}{lcccccc}
\hline Households Receiving SNAP & $\begin{array}{c}\text { Admin. } \\
\text { Data }\end{array}$ & TRIM3 & $\begin{array}{c}\text { CI } \\
+/-\end{array}$ & CPS & $\begin{array}{c}\text { CI } \\
+/-\end{array}$ \\
\hline Mean & $17.9 \%$ & & $18.3 \%$ & 0.4 & $11.1 \%$ & 0.2 \\
\hline $\begin{array}{l}\text { Characteristics of Units } \\
\text { Receiving SNAP }\end{array}$ & SNAP QC & $\begin{array}{c}\text { CI } \\
+/-\end{array}$ & TRIM3 & $\begin{array}{c}\text { CI } \\
+/-\end{array}$ & CPS & $\begin{array}{c}\text { CI } \\
+/-\end{array}$ \\
\hline HH w/ Children & $42.7 \%$ & 0.4 & $48.5 \%$ & 0.8 & $49.9 \%$ & 1.1 \\
HH w/ Children Under Age 5 & $20.9 \%$ & 0.4 & $21.7 \%$ & 0.7 & $23.4 \%$ & 0.9 \\
HH w/ Children Age 6-17 & $33.9 \%$ & 0.4 & $40.1 \%$ & 0.8 & $41.2 \%$ & 1.0 \\
HH/ with Age 60+ & $19.6 \%$ & 0.3 & $25.2 \%$ & 0.7 & $27.8 \%$ & 1.0 \\
Noncitizen in HH & $6 \%$ & 0.2 & $13.9 \%$ & 0.6 & $13.3 \%$ & 0.7 \\
Metropolitan Locality & $82.2 \%$ & & $82.4 \%$ & 0.6 & $81.4 \%$ & 0.8 \\
Receiving TANF & $5.8 \%$ & 0.2 & $7.2 \%$ & 0.3 & $7.8 \%$ & 0.6 \\
Receiving SSI & $20.5 \%$ & 0.4 & $20.1 \%$ & 0.4 & $20.8 \%$ & 0.6 \\
Receiving Social Security & $24.5 \%$ & 0.4 & $26.3 \%$ & 0.4 & $32.5 \%$ & 0.7
\end{tabular}

Note: SNAP QC: SNAP Quality Control sample (Gray et al. 2015). SNAP QC estimates are based on annual data (sample size of 48,022 households) while CPS/TRIM based on 12-month reference period. Administrative data refers to U.S. Department of Agriculture Food and Nutrition Service report on share of households receiving SNAP benefits in FY2015. Confidence intervals (CI) indicate 95 percent confidence intervals on each estimate. Confidence interval for Metropolitan Locality for SNAP QC estimates cannot be obtained, as the variable is not retained in the public-use file.

According to the QC sample, about 42.7 percent of SNAP households contained children, and around 21 percent contained children under the age of 5. The unadjusted and TRIM3-adjusted CPS ASEC feature similar patterns with respect to the characteristics of SNAP households: relative to the QC sample, they both overestimate the share of SNAP households with children (around 49 percent).

Relative to the unadjusted CPS, the TRIM3-adjusted benefits more closely match the SNAP QC surveys with respect to the share of households featuring an individual over the age of 60 (around 20 percent), and the share of households receiving Social Security benefits. For most characteristics, however, the differences between TRIM3 and unadjusted CPS ASEC estimates are not statistically different from zero (living in a metropolitan area, the share of 
households receiving TANF or SSI, and households with non-citizens). In other words, the composition of households receiving SNAP benefits after the TRIM3-adjustments is generally comparable to the composition of households receiving SNAP benefits before the adjustments.

Which demographic groups benefit the most from the TRIM3 adjustments? In Appendix II, I present, for each of the three programs examined, the conditional median value of the benefit among households receiving the benefit and the coverage rate of the benefit, defined as the share of households receiving any value of the benefit during the year. For each of the three programs, we see that households with children see greater increases in estimated coverage rate relative to households without children. The share of households with children receiving SNAP benefits, for example, jumps from 17.9 to 28.8 percent with the TRIM3-adjusted benefits. The share of households with children receiving TANF benefits increases from 2 to 4.4 percent, while the share receiving SNAP benefits increases from 3.5 to 6 percent.

Finally, I examine the gross household income distribution of SNAP, TANF, and SSI beneficiaries before and after the TRIM3 adjustments. Here, gross household income includes all cash income (for example, market earnings, pension benefits, child support payments, gains from unemployment insurance, and more) but excludes transfers from SNAP, TANF, and SSI. ${ }^{7}$ As detailed in the prior section, national-level administrative records do not provide a detailed portrait of the income breakdown of households receiving benefit transfers. As such, I only compare the income distribution of the benefit recipients in the TRIM3-adjusted CPS ASEC versus the unadjusted version. Figure 2 presents the comparisons.

\footnotetext{
${ }^{7}$ Removing SNAP, TANF, and SSI transfers from income provides a clearer account of to whom the TRIM3adjusted benefits are being transferred. If I were to already take the transfers into account, this would affect the underlying income distribution (the X-axes of Figure 2). For example, the zero-income households receiving SNAP benefits would no longer appear as zero-income households if SNAP benefits were already included.
} 
Figure 2: Benefit Participation Rates by Gross Household Income Percentile, Before \& After Applying TRIM3 Adjustments (2015)

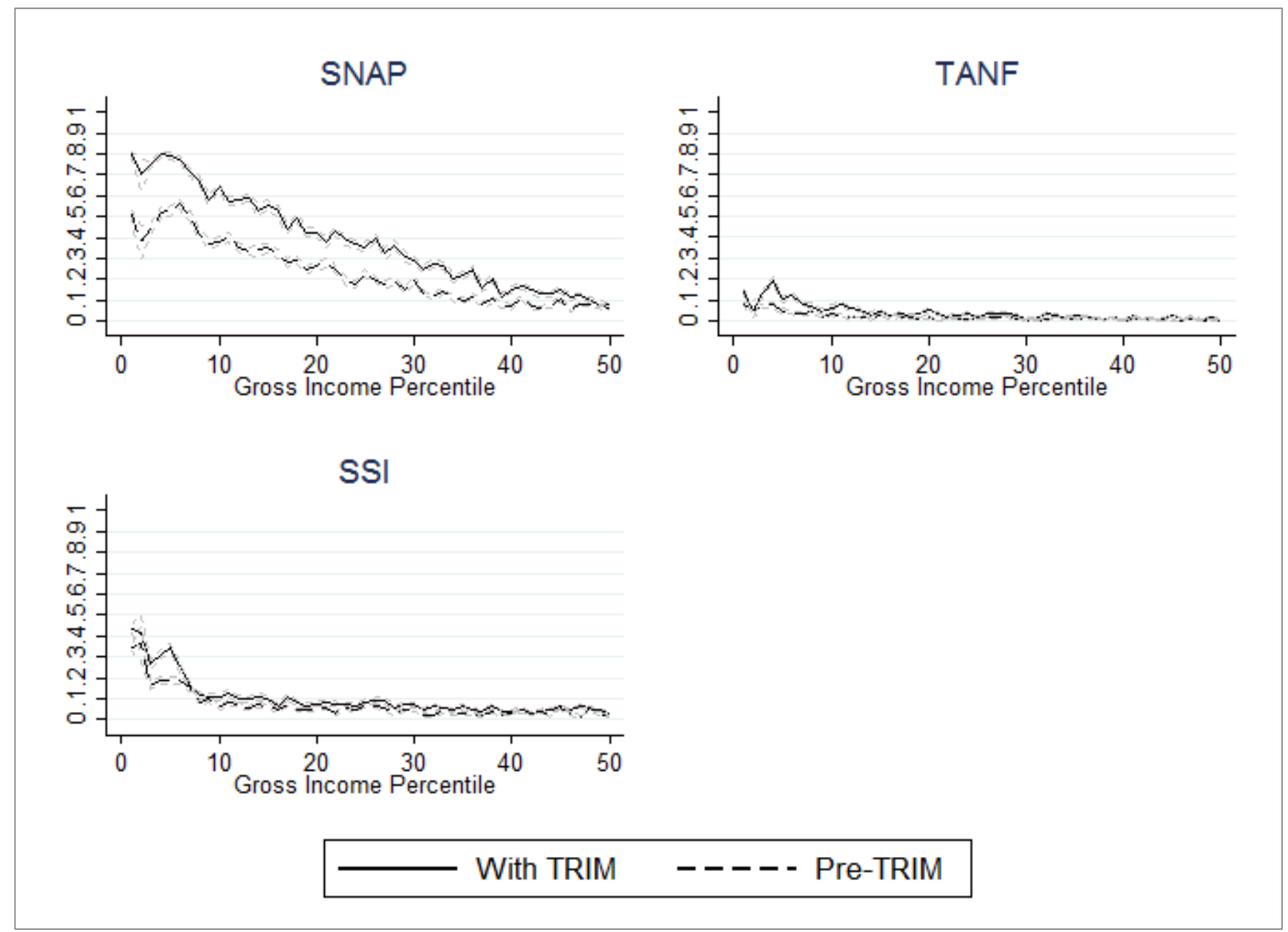

Note: Light gray bars represent lower- and upper-bounds of 95 percent confidence intervals. Gross household income includes all cash income except transfers from SNAP, TANF, and SSI.

For TANF and SSI, differences in benefit receipt before and after TRIM3 are statistically significant among households with zero gross incomes, and then from around the $5^{\text {th }}$ to the $15^{\text {th }}$ percentile of the gross income distribution. In other words: though the TRIM3 adjustments assign TANF or SSI benefits to many households across the distribution, the differences are particularly concentrated among households with annual gross incomes at the $15^{\text {th }}$ percentile and lower.

SNAP stands out relative to TANF or SSI, as the program covers many more households compared to the other two programs. Even in the unadjusted CPS ASEC, for example, we see that around 50 percent of households with zero gross income in 2015 are estimated to have 
received SNAP benefits during the year. After applying the TRIM3 adjustments, however, that jumps to nearly 80 percent of households. This finding may be an indication of TRIM3's tendency to over-impute SNAP benefits to lower-income households, as Stevens et al. (2018) identified in their comparison of TRIM3 and administrative records across seven states. If so, this would have implications for the imputations' effects on poverty estimates: if TRIM3 overimputes SNAP benefits to households living with very low incomes (rather than to households above the poverty line), the TRIM3 adjustments may overstate the poverty-reduction effect of SNAP benefits. I return to this possibility in the next section.

Still, it is worth considering that individuals with zero annual gross income compose only around 7 percent of all SNAP recipients in 2015 (this is true for both the TRIM3 and pre-TRIM3 distributions of SNAP households). In contrast, the SNAP QC reports suggest that more than 20 percent of households receiving SNAP have zero monthly gross income in 2015. The TRIM3-adjusted estimates in the CPS ASEC would be plausible, then, if around one-third of the SNAP households reporting zero monthly income remain without reportable income for the full calendar year. Beyond the first percentile, we see that the TRIM3 adjustments predict higher levels of SNAP participation up until around the $50^{\text {th }}$ percentile of the gross income distribution. In both the pre- and post-TRIM3 distribution of SNAP households, estimated participation in SNAP declines near-linearly as gross household income increases. In fact, the relative income distribution of SNAP beneficiaries is near-identical before and after the TRIM3 adjustments. At each percentile in the bottom half of the gross income distribution, however, participation in SNAP is higher after the benefit adjustments. 


\section{Re-Estimating Poverty Rates with TRIM-Adjusted Benefits}

Figure 3 now presents updated poverty rates for the total population and among children in 2015 after applying the TRIM3 adjustments. As discussed previously, I present estimates for both the SPM and the percent-of-median concepts.

Figure 3: Estimates of Poverty Before \& After TRIM3 Imputations (2015)

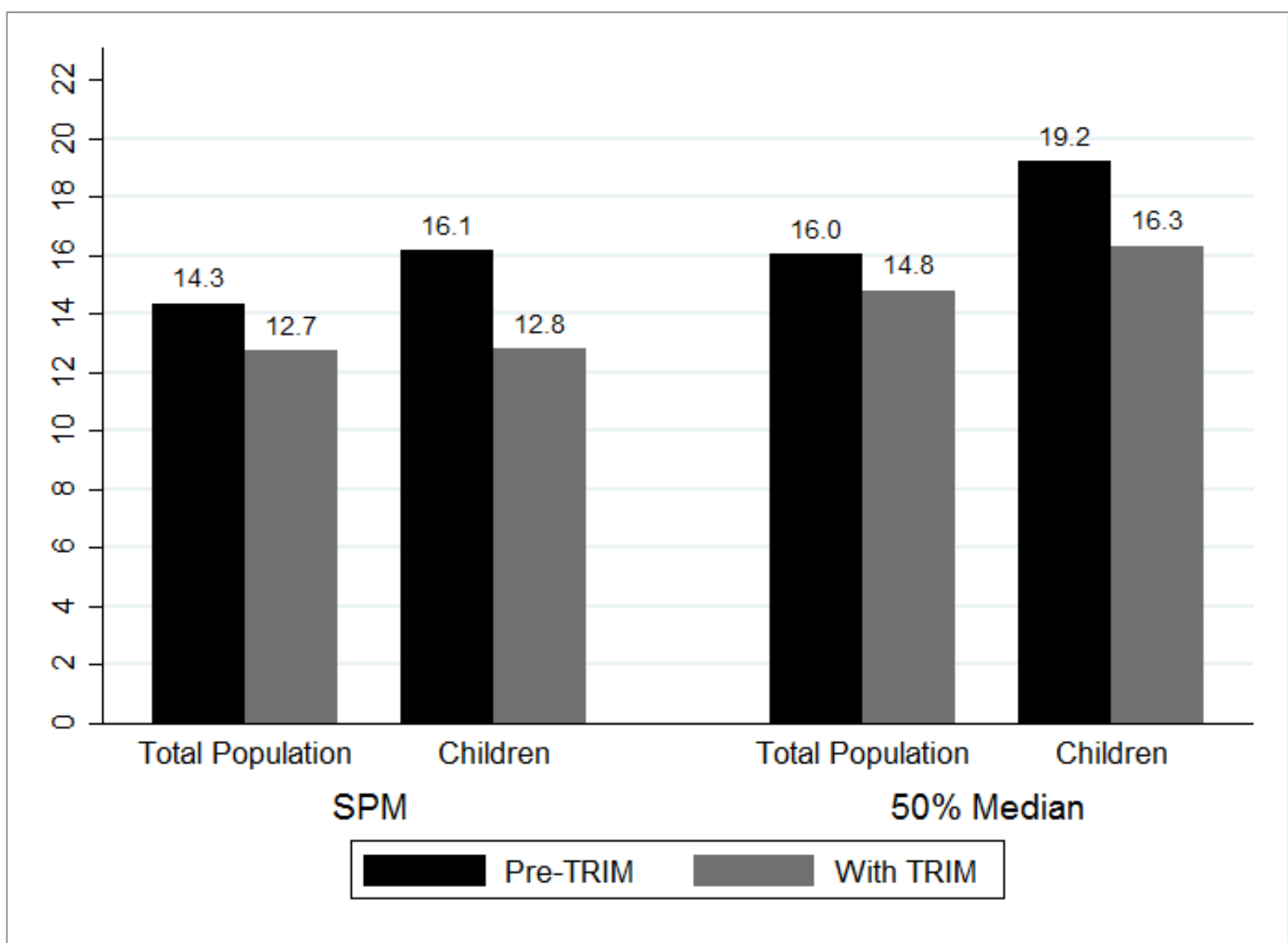

Note: All differences in pre/post-TRIM3 poverty estimates are statistically significant. 95\% confidence intervals for child poverty estimates are about 0.3 percent; intervals for total population estimates are about 0.2 percent. SPM = Supplemental Poverty Measure. $50 \%$ Median = poverty threshold set at 50 percent of national equivalized household median income. Data: CPS ASEC. TRIM imputations adjust for underreporting of TANF, SNAP, and SSI.

Figure 3 shows notable and statistically significant differences in poverty rates before and after adjusting for benefit underreporting. The left half of the figure shows poverty estimates measured with the SPM. For the total population, the estimated poverty rate using the SPM falls from 14.3 to 12.7 percent after applying the benefit adjustments, a relative decline of 
11.1 percent. Children are particularly affected: child poverty estimates fall drop from 16.1 to 12.8 percent, a decline of 3.3 percentage points (20 percent) with the TRIM3-adjusted benefits.

Poverty rates estimated with the percent-of-median concept are higher than the SPM estimates. The differences before and after the benefit adjustments, however, are similar. Examining the total population in 2015 , the estimated poverty rate falls from 16 to 14.8 percent - a decline of 1.2 percentage points (7.7 percent) after adjusting for underreporting. Again, the declines are even greater when re-calculating child poverty estimates. The estimated child poverty rate falls from 19.2 to 16.3 percent, a 2.9 percentage point (15 percent) decline. In Appendix III, I decompose the overall changes in post-TRIM3 poverty rates by transfer program (SNAP, TANF, and SSI). For the SPM, the TRIM3 adjustments for SNAP benefits were responsible for about two-thirds of the total poverty reduction for the total population (1 percentage point of the total 1.6 percentage point change after applying TRIM3). For the percent-of-median measure, the SNAP adjustments were responsible for about three-fourths of the total reduction ( 0.9 percentage points of the total 1.2 percentage point change). In contrast, the pre-post differences in poverty estimates after only adjusting for TANF benefits are not statistically different from zero.

In Table 3, I present re-estimates of poverty rates for children in single-parent households, children in two-households, for adults (age 18 to 64), and for the age 65+ demographic. It is well established that children in single-parent households (and single mother households, in particular) face a greater likelihood of living in poverty. Cross-national research demonstrates that this is especially true in the United States (Brady et al. 2017). At the same time, single-parent households are particularly likely to utilize TANF and SNAP benefits and, thus, may be more affected by the underreporting of these two benefits in the unadjusted CPS ASEC. 
Table 3: Estimates of Poverty Before \& After TRIM Imputations by Subpopulation (2015)

\begin{tabular}{lccccc}
\hline \multicolumn{1}{l}{ Supplemental Poverty Measure $(S P M)$} & & & & \\
\hline & $\begin{array}{c}\text { Before } \\
\text { TRIM }\end{array}$ & $\begin{array}{c}\text { With } \\
\text { TRIM }\end{array}$ & $\begin{array}{c}\text { Percentage } \\
\text { Pt. Change }\end{array}$ & $\begin{array}{c}\text { Relative } \\
\text { Change }\end{array}$ & Signif. \\
Children in Single-Parent HH & $27.8 \%$ & $21.8 \%$ & -6.0 & $-21.6 \%$ & $*$ \\
Children in Two-Parent HH & $11.3 \%$ & $9.1 \%$ & -2.3 & $-20.1 \%$ & $*$ \\
Age 18-64 & $13.8 \%$ & $12.6 \%$ & -1.2 & $-8.7 \%$ & $*$ \\
Age 65+ & $13.7 \%$ & $13.3 \%$ & -0.4 & $-2.8 \%$ & \\
Total Population & $14.3 \%$ & $12.7 \%$ & -1.6 & $-11.1 \%$ & $*$ \\
\hline
\end{tabular}

$50 \%$ Federal Median Income

\begin{tabular}{lccccc}
\hline & $\begin{array}{c}\text { Before } \\
\text { TRIM }\end{array}$ & $\begin{array}{c}\text { With } \\
\text { TRIM }\end{array}$ & $\begin{array}{c}\text { Percentage } \\
\text { Pt. Change }\end{array}$ & $\begin{array}{c}\text { Relative } \\
\text { Change }\end{array}$ & Signif. \\
Children in Single-Parent HH & $36.1 \%$ & $31.4 \%$ & -4.7 & $-13.0 \%$ & $*$ \\
Children in Two-Parent HH & $12.3 \%$ & $10.1 \%$ & -2.2 & $-17.7 \%$ & $*$ \\
Age 18-64 & $14.2 \%$ & $13.4 \%$ & -0.8 & $-5.8 \%$ & $*$ \\
Age 65+ & $18.9 \%$ & $18.7 \%$ & -0.3 & $-1.4 \%$ & \\
Total Population & $16.0 \%$ & $14.8 \%$ & -1.2 & $-7.7 \%$ & $*$ \\
\hline
\end{tabular}

Note: TRIM3 adjustments adjust for the underreporting of SNAP, TANF, and SSI benefits. Approximately 21 percent of children lived in single-parent households in 2015. Using the SPM, overall child poverty rates fell from 16.1 to 12.8 percent (see Figure 3). Using the percent-of-median measure, child poverty rates fell from 19.2 to 16.3 percent after TRIM adjustments. Asterisks (*) in "Signif." Column indicate that difference is statistically significant (95 percent confidence).

For poverty rates estimated with the SPM, the share of children in single-parent households living in poverty falls from 27.8 to 21.8 percent ( 6 percentage point decline) with the TRIM3 imputations. This is a relative decline of more than 21 percent - higher than for any other household type examined. The percent-of-median concept shows a slightly different pattern: poverty among children in single-parent households falls by 4.7 percentage points, or 13 percent (36.1 to 31.4 percent). Thus, poverty in single-parent households is likely less prevalent than the unadjusted CPS ASEC suggests. At the same time, children in two-parent households also see large reductions in estimated poverty rates. Using the SPM, poverty among 
children in two-parent homes falls from 11.3 to 9.1 percent $(2.3$ percentage points, or 20 percent); for the percent-of-median measure, it falls from 12.3 to 10.1 percent (2.2 percentage points, or 17.7 percent).

Adults between the ages of 18 and 64 see smaller, but still statistically significant, declines in estimated poverty rates. The TRIM3 imputations lead to a 2.2 percentage point, or 8.7 percent, decline (13.8 to 12.6 percent) in working-age poverty when measured with the SPM, and a 0.8 percentage point, or 5.8 percent, decline (14.2 to 13.4 percent) when measured as 50 percent of median income. The changes in poverty estimates among individuals aged 65 and over are not statistically significant for either measure of poverty. Again, this is not surprising: SNAP and TANF benefits are concentrated among low-income households with children, and such households are less likely to contain retirement-age adults.

In Appendix I (Table A2), I present re-estimates of poverty rates across each of the 50 states and Washington, D.C. I again use a three-year average (2013 to 2015) to increase sample sizes and reduce standard errors. For simplicity, I only present estimates for the total population. Researchers interested in obtaining disaggregated poverty estimates at the state level, however, can use the documentation provided in Appendix IV to replicate and extend the findings presented here.

\section{DISCUSSION \& CONCLUSION}

Despite longstanding evidence of benefit underreporting in the CPS ASEC, few researchers have evaluated or utilized the publicly-available methods for generating more accurate estimates of household income. As a result, estimates derived from the unadjusted CPS ASEC data are likely to overstate the incidence of poverty in the U.S. Equally concerning, these estimates may misrepresent the demographic characteristics of individuals living beneath the poverty line. This paper applied the Urban Institute's TRIM3 simulation model to address the underreporting of SNAP, TANF, and SSI benefits. Relative to the unadjusted CPS ASEC, 
which fails to capture roughly half of allocated SNAP and TANF benefits in recent years, the TRIM3-adjusted benefits align more closely with administrative records on benefit participation and benefit levels. However, there remains a risk that the TRIM3-adjusted benefits for SNAP, in particular, are over-allocated toward lower-income households. As a consequence, the benefit adjustments may lead to lower estimates of poverty than administrative records, if available across all 50 states, would suggest.

A central purpose of this paper is to make the benefit imputations more accessible for future research. In Appendix IV, documentation is provided for researchers to apply the TRIM3 imputations to the CPS ASEC in their own work. Thus, scholars can build off the key findings presented here to continue to assess the relative accuracy and anti-poverty effect of the adjusted benefit estimates. This paper's findings demonstrate why more frequent application of the benefit adjustments is necessary: when calculating poverty rates using the TRIM3-adjusted data, the overall poverty rate falls from 14.3 to 12.7 percent when measured with the Supplemental Poverty Measure, and from 16 to 14.8 percent when using the relative measure of poverty applied frequently in cross-national research. In absolute terms, the differences equate to between 23 to 35 million Americans misclassified as living in poverty in 2015, depending on the poverty concept applied. The reductions in poverty rates are particularly large among children: child poverty rates measured with the SPM fall from 16.1 to 12.8 percent after applying the TRIM3 benefit adjustments.

Though the TRIM3-adjusted benefits applied here greatly improve the sum of transfer benefits measured in the CPS ASEC data, probability-based imputations remain an imperfect solution to the issue of benefit underreporting. To start, the benefit imputations introduce new possibilities for measurement error in their attempt to address benefit underreporting. Specifically, imperfections in the imputation process can assign transfer benefits to households who do not in reality receive them, or can systematically over-assign transfer benefits toward 
low-income households. Indeed, Stevens et al. (2018) find this is the case for TRIM3-adjusted SNAP benefits in seven states. Due to the over-allocation of SNAP benefits to households beneath the poverty line, the TRIM3 adjustments actually over-corrected poverty estimates in their sample (compared to the poverty estimates suggested by the authors' administrative records on household income). Probability-based imputations thus come at a cost. While the adjusted data more accurately measure the sum of means-tested benefits allocated to the population, and while the number of 'true positives' (individuals receiving benefits in the survey data and in reality) increases, the number of false positives (receiving benefits in the survey data but not in reality) also increases (Stevens et al. 2018). As emphasized before, the direct integration of administrative data would be preferable to probability-based imputations. However, the current capabilities of integrated administrative data do not allow for nation-wide estimates of poverty using adjusted SNAP, TANF, and SSI benefits. In the latest step forward in the use of integrated records, improved SNAP estimates were only available for 12 states, and improved TANF estimates for 30 states (Meyer and $\mathrm{Wu} 2018$ ). Until the use of administrative data is publicly-available across each of the United States, the TRIM3-adjusted benefits provide researchers an intermediate approach to producing more precise estimates of the incidence of poverty at the national level. Still, the benefit adjustments must be acknowledged as an imperfect solution and interpreted with caution.

Though this paper focuses primarily on measurement error within transfer income, other measurement concerns within survey data may still affect estimates of the household income distribution. As mentioned previously, the misreporting of earnings, particularly among parttime or infrequent workers, may overstate the incidence of poverty if these workers tend to be below the poverty threshold (Weinberg 2004). Beyond income misreporting, sampling challenges make it difficult for surveys to capture the very poor (such as many homeless individuals) or the very rich (Burkhauser et al. 2018). With particular concern for European 
income data, the exclusion of sampling design variables within the microdata can complicate the calculation of precise standard errors and confidence intervals around poverty estimates (Goedemé 2013). Measurement challenges abound, and continued research is needed to improve the quality and reliability of survey-based income information.

The improvement of survey data also opens up the opportunity for new research. In cross-national analyses of poverty, the U.S. is considered an outlier due to its high levels of poverty relative to other EU or OECD Member States. To what extent do such findings hold, however, when issues of benefit underreporting are addressed? The benefit adjustments might also affect findings with respect to intra-U.S. analyses of poverty. Fox et al. (2014) have extended the SPM poverty rate to the late 1960s, finding that poverty has declined throughout recent decades. Given the effects of underreporting on estimates of SPM poverty, and that underreporting appears to have increased over time, the authors' findings might still underestimate the decline of poverty in recent years.

Beyond the overall incidence of poverty, researchers can use the improved data to evaluate the veracity of prior conclusions of the demographic composition of poverty. Much of the poverty literature for example, has focused on the relationship between family structure such as single motherhood - and the likelihood of poverty (Brady et al. 2017). As this study shows, however, the underreporting of means-tested transfers is particularly consequential for lone-parent households. When applying the benefit adjustments, the SPM rate among singleparent households falls from 27.8 to 21.8 percent - a greater relative decline than any other subgroup examined. To be sure, children in single-parent households remain likelier than those in two-parent households to live in poverty. However, the findings presented here suggest that social transfers do more than previously observed to reduce the likelihood that a single parent lives beneath the poverty line. 
Finally, researchers should continue to assess the veracity of the benefit adjustments relative to administrative records or other sources of information on the characteristics of benefit recipients. In this study, I utilized SNAP quality control reports and administrative data on participation and spending levels to assess the reliability of the TRIM3-adjusted benefits. As administrative micro-data on benefit recipients becomes more accessible across a larger number of states, future studies should evaluate in greater detail the income situation and demographic characteristics of SNAP, SSI, and TANF recipients. This would be useful in investigating the structure of underreporting within household surveys, as well as for further assessing the accuracy of imputation-based procedures in addressing the issue of underreporting. 


\section{REFERENCES}

Atkinson, A. (1998). Poverty In Europe. Oxford: Blackwell.

Bee, C. A., Gathright, G. M. R., \& Meyer, B. D. (2015). Bias from Unit Non-Response in the Measurement of Income in Household Surveys. University of Chicago Harris School of Public Policy.

Bee, C. A., \& Mitchell, J. (2017). Do Older Americans Have More Income Than We Think? . U.S. Census Bureau: Social, Economic, and Housing Statistics Division Working Paper, 2017-39.

Bishaw, A. (2017). How the Census Bureau Measures Poverty: With Selected Sources of Poverty data. U.S. Census Bureau.

Bitler, M., Hoynes, H., \& Kuka, E. (2017). Child Poverty, the Great Recession, and the Social Safety Net in the United States. Journal of Policy Analysis and Management, 36(2), 358-389, doi:10.1002/pam.21963.

Bound, J., Brown, C., \& Mathiowetz, N. (2001). Measurement error in survey data. In J. J. Heckman, \& E. E. Leamer (Eds.), Handbook of Econometrics (Vol. 5, pp. 3705-3843): Elsevier.

Bound, J., \& Krueger, A. B. (1991). The Extent of Measurement Error in Longitudinal Earnings Data: Do Two Wrongs Make a Right? Journal of Labor Economics, 9(1), 124.

Brady, D. (2009). Rich democracies, poor people : how politics explain poverty. Oxford ; New York: Oxford University Press.

Brady, D., \& Destro, L. M. (2014). Poverty. In D. Beland, C. Howard, \& K. J. Morgan (Eds.), The Oxford Handbook of U.S. Social Policy (pp. 585-602). New York, NY: Oxford University Press.

Brady, D., Finnigan, R., \& Hübgen, S. (2017). Rethinking the Risks of Poverty: A Framework for Analyzing Prevlances and Penalties. American Journal of Sociology.

Burkhauser, R. V., Hérault, N., Jenkins, S. P., \& Wilkins, R. (2018). Survey Under-Coverage of Top Incomes and Estimation of Inequality: What is the Role of the UK's SPI Adjustment? Fiscal Studies, 39(2), 213-240, doi:doi:10.1111/1475-5890.12158.

Cantillon, B., \& Vandenbroucke, F. (2014). Reconciling work and poverty reduction : how successful are European welfare states? (International policy exchange series). Oxford: New York : Oxford University Press.

Chen, W.-H., \& Corak, M. (2005). Child Poverty and Changes in Child Poverty in Rich Countries Since 1990. UNICEF Innocenti Working Paper, 2005-02.

Corak, M. (2005). Principles and Practicalities for Measuring Child Poverty in the Rich Countries. IZA Working Papers(DP No. 1579).

Decancq, K., Fleurbeay, M., \& Maniquet, F. (2015). Multidimensional poverty measurement with individual preferences. CORE Discussion Papers.

Flood, S., King, M., Ruggles, S., \& Warren, J. R. (2018). Integrated Public Use Microdata Series, Current Population Survey: Version 6.0. [dataset]. Minnesota: University of Minnesota.

Foster, J. E. (1998). Absolute versus Relative Poverty. The American Economic Review, 88(2), 335-341.

Fox, L., Garfinkel, I., Kaushal, N., Waldfogel, J., \& Wimer, C. (2014). Waging War on Poverty Historical Trends in Poverty Using the Supplemental Poverty Measure. NBER working paper 19789. Cambridge, Mass.: National Bureau of Economic Research,.

Fox, L., Heggeness, M., Pacas, J., \& Stevens, K. (2017). Using SNAP Administrative Records to Evaluate Poverty Measurement. U.S. Census Bureau, Working Paper Number: SEHSD-WP2017-49. 
Fox, L., \& Renwick, T. (2016). The Supplemental Poverty Measure: 2015. U.S. Census Bureau, Current Population Reports.

Goedemé, T. (2013). How much Confidence can we have in EU-SILC? Complex Sample Designs and the Standard Error of the Europe 2020 Poverty Indicators. [journal article]. Social Indicators Research, 110(1), 89-110, doi:10.1007/s11205-011-9918-2.

Gornick, J. C., \& Jäntti, M. (2012). Child poverty in cross-national perspective: Lessons from the Luxembourg Income Study. Children and Youth Services Review, 34(3), 558-568, doi:https://doi.org/10.1016/j.childyouth.2011.10.016.

Gray, K. F., Fisher, S., \& Lauffer, S. (2015). Characteristics of Supplemental Nutrition Assistance Program Households: Fiscal Year 2015. U.S. Department of Agriculture.

Haskins, R., \& Sawhill, I. (2009). Creating an Opportunity Society. Washington, D.C.: Brookings Institution Press.

Henry, M., Shivji, A., de Sousa, T., Cohen, R., \& Abt Associates (2015). The 2015 Annual Homeless Assessment Report (AHAR) to Congress. The U.S. Department of Housing and Urban Development Office of Community Planning and Development.

Jäntti, M., Veli-Matti, T., \& Marlier, E. (2013). The use of registers in the context of EUSILC: challenges and opportunities. Eurostat Statistical Working Papers.

Kapteyn, A., Ypma, J., xa, \& Y (2007). Measurement Error and Misclassification: A Comparison of Survey and Administrative Data. Journal of Labor Economics, 25(3), 513-551, doi:10.1086/513298.

Kasprzyk, D. (2005). Measurement Error in Household Surveys: Sources and Measurement. Mathematica Policy Research.

Keith-Jennings, B. (2012). SNAP Plays a Critical Role in Helping Children. Center on Budget \& Policy Priorities.

Kristensen, N., \& Westergard-Nielsen, N. (2006). A Large-Scale Validation Study of Measurement Errors in Longitudinal Survey Data. IZA Discussion Paper Series, 2939(Institute for the Study of Labor (IZA)).

Meyer, B. D., \& Mittag, N. (2015). Using Linked Survey and Administrative Data to Better Measure Income: Implications for Poverty, Program Effectiveness and Holes in the Safety Net. National Bureau of Economic Research Working Paper Series, No. 21676, doi:10.3386/w21676.

Meyer, B. D., \& Sullivan, J. X. (2006). Consumption, Income, and Material Well-Being After Welfare Reform. National Bureau of Economic Research Working Paper Series, No. 11976, doi:10.3386/w11976.

Meyer, B. D., Wallace, K. C. M., \& Sullivan, J. X. (2009). The Under-Reporting of Transfers in Household Surveys: Its Nature and Consequences. National Bureau of Economic Research Working Paper Series, No. 15181.

Meyer, B. D., \& Wu, D. (2018). The Poverty Reduction of Social Security and Means-Tested Transfers. National Bureau of Economic Research Working Paper Series, No. 24567, doi:10.3386/w24567.

Mittag, N. (2016). Correcting for Misreporting of Government Benefits. IZA Discussion Paper Series(No. 10266).

Moore, J. C., Stinson, L., \& Welniak Jr., E. J. (2000). Income Measurement Error in Surveys: A Review. Journal of Official Statistics, 16(4), 331-361.

Nicoletti, C., Peracchi, F., \& Foliano, F. (2011). Estimating Income Poverty in the Presence of Missing Data and Measurement Error. Journal of Business \& Economic Statistics, 29(1), 61-72.

Nolan, B., \& Whelan, C. T. (2011). Poverty and deprivation in Europe. Oxford: Oxford University Press. 
Office of Family Assistance (2015). State TANF Spending in FY 2015. U.s. Department of Health \& Human Services: Administration for Children \& Families.

Provencher, A. J. (2011). Unit of Analysis for Poverty Measurement: A Comparison of the Supplemental Poverty Measure and the Official Poverty Measure. Paper presented at the 2011 Joint Statistical Meetings,

Rainwater, L., \& Smeeding, T. M. (2003). Poor Kids in a Rich Country: America's Children in Comparative Perspective: Russell Sage Foundation.

Rodgers, W. L., Brown, C., \& Duncan, G. J. (1993). Errors in Survey Reports of Earnings, Hours Worked, and Hourly Wages. Journal of the American Statistical Association, 88(424), 1208-1218, doi:10.1080/01621459.1993.10476400.

Social Security Administration (2017). SSI Annual Statisitical Report, 2015. Social Security: Research, Statistics, \& Policy Analysis.

Stevens, K., Fox, L., \& Heggeness, M. (2018). Precision in Measurement: Using State-Level SNAP Administrative Records and the Transfer Income Model (TRIM3) to Evaluate Poverty Measurement. U.S. Census Bureau, Working Paper Number: SEHSDWP2018-15.

U.S. Census Bureau (1992). Measuring the Effect of Benefits and Taxes on Income and Poverty: 1992. U.S. Census Bureau, P60-186RD.

U.S. Department of Agriculture (2017). Supplemental Nutrition Assistance Program (SNAP): National Level Annual Summary. USDA Food \& Nutrition Service.

Weinberg, D. H. (2004). Income Data Quality Issues in the Annual Social and Economic Supplement to the Current Population Survey. Paper presented at the American Enterprise Institute-University of Maryland Seminar on Poverty Measurement, College Park, Maryland,

Wheaton, L. (2008). Underreporting of Means-Tested Transfer Programs in the CPS and SIPP. The Urban Institute.

Wheaton, L., \& Tran, V. (2018). The Antipoverty Effects of the Supplemental Nutrition Assistance Program. The Urban Institute, Research Report.

Winship, S. (2016). Poverty After Welfare Reform. Manhattan Institute.

Zedlewski, S., \& Giannarelli, L. (2015). TRIM: A Tool for Social Policy Analysis. The Urban Institute. 
APPENDIX I: State-Level Estimates of Poverty \& Underreporting

Table A1: Benefit Underreporting by State Before \& After TRIM3 Adjustments (Three-Year Average, 2013 to 2015)

\begin{tabular}{|c|c|c|c|c|c|c|}
\hline \multirow[b]{2}{*}{ State } & \multicolumn{2}{|c|}{$\begin{array}{c}\text { SNAP } \\
(2013-2015 \text { Avg. })\end{array}$} & \multicolumn{2}{|c|}{$\begin{array}{c}\text { TANF } \\
(2013-2015 \text { Avg. })\end{array}$} & \multicolumn{2}{|c|}{$\begin{array}{c}\text { SSI } \\
(2013-2015 \text { Avg. })\end{array}$} \\
\hline & $\begin{array}{l}\text { \% Measured } \\
\text { in CPS }\end{array}$ & $\begin{array}{l}\% \text { Measured } \\
\text { with TRIM3 }\end{array}$ & $\begin{array}{l}\text { \% Measured } \\
\text { in CPS }\end{array}$ & $\begin{array}{l}\% \text { Measured } \\
\text { with TRIM3 }\end{array}$ & $\begin{array}{l}\text { \% Measured } \\
\text { in CPS }\end{array}$ & $\begin{array}{l}\% \text { Measured } \\
\text { with TRIM3 }\end{array}$ \\
\hline Alabama & $54.9 \%$ & $86.4 \%$ & $128.6 \%$ & $84.5 \%$ & $70.1 \%$ & $75.9 \%$ \\
\hline Alaska & $52.3 \%$ & $91.6 \%$ & $31.8 \%$ & $60.8 \%$ & $87.7 \%$ & $118.1 \%$ \\
\hline Arizona & $62.4 \%$ & $96.7 \%$ & $95.4 \%$ & $129.4 \%$ & $87.2 \%$ & $101.4 \%$ \\
\hline Arkansas & $58.7 \%$ & $97.1 \%$ & $52.3 \%$ & $122.5 \%$ & $87.6 \%$ & $85.1 \%$ \\
\hline California & $49.8 \%$ & $87.1 \%$ & $41.3 \%$ & $93.4 \%$ & $65.3 \%$ & $92.0 \%$ \\
\hline Colorado & $63.7 \%$ & $99.2 \%$ & $53.6 \%$ & $103.9 \%$ & $108.5 \%$ & $93.3 \%$ \\
\hline Connecticut & $62.7 \%$ & $87.0 \%$ & $55.6 \%$ & $91.1 \%$ & $107.6 \%$ & $93.1 \%$ \\
\hline Delaware & $49.1 \%$ & $79.6 \%$ & $48.8 \%$ & $86.4 \%$ & $93.8 \%$ & $89.3 \%$ \\
\hline Florida & $44.9 \%$ & $83.4 \%$ & $58.4 \%$ & $81.4 \%$ & $76.7 \%$ & $85.6 \%$ \\
\hline Georgia & $46.0 \%$ & $81.7 \%$ & $126.6 \%$ & $76.3 \%$ & $66.0 \%$ & $89.5 \%$ \\
\hline Hawaii & $43.0 \%$ & $97.0 \%$ & $24.4 \%$ & $66.6 \%$ & $70.2 \%$ & $82.2 \%$ \\
\hline Idaho & $46.6 \%$ & $89.3 \%$ & $83.6 \%$ & $113.3 \%$ & $91.4 \%$ & $93.7 \%$ \\
\hline Illinois & $44.3 \%$ & $76.1 \%$ & $127.3 \%$ & $78.1 \%$ & $63.0 \%$ & $79.6 \%$ \\
\hline Indiana & $50.4 \%$ & $87.0 \%$ & $161.7 \%$ & $134.3 \%$ & $111.3 \%$ & $99.2 \%$ \\
\hline Iowa & $50.4 \%$ & $84.7 \%$ & $66.1 \%$ & $94.3 \%$ & $104.4 \%$ & $108.5 \%$ \\
\hline Kansas & $69.4 \%$ & $102.3 \%$ & $60.1 \%$ & $80.2 \%$ & $103.3 \%$ & $89.7 \%$ \\
\hline Kentucky & $54.6 \%$ & $93.0 \%$ & $28.9 \%$ & $64.7 \%$ & $89.1 \%$ & $89.8 \%$ \\
\hline Louisiana & $51.4 \%$ & $86.6 \%$ & $143.6 \%$ & $70.5 \%$ & $69.0 \%$ & $88.8 \%$ \\
\hline Maine & $69.4 \%$ & $94.0 \%$ & $68.9 \%$ & $59.5 \%$ & $107.2 \%$ & $92.7 \%$ \\
\hline Maryland & $46.7 \%$ & $74.7 \%$ & $58.8 \%$ & $88.0 \%$ & $70.1 \%$ & $79.0 \%$ \\
\hline Massachusetts & $63.5 \%$ & $94.7 \%$ & $37.8 \%$ & $79.7 \%$ & $115.9 \%$ & $113.2 \%$ \\
\hline Michigan & $56.1 \%$ & $87.3 \%$ & $57.1 \%$ & $67.2 \%$ & $79.3 \%$ & $81.2 \%$ \\
\hline Minnesota & $57.0 \%$ & $93.8 \%$ & $71.1 \%$ & $96.1 \%$ & $88.5 \%$ & $88.0 \%$ \\
\hline Mississippi & $63.8 \%$ & $87.6 \%$ & $191.8 \%$ & $93.2 \%$ & $92.1 \%$ & $103.9 \%$ \\
\hline Missouri & $51.1 \%$ & $80.2 \%$ & $61.0 \%$ & $95.3 \%$ & $100.9 \%$ & $78.9 \%$ \\
\hline Montana & $53.6 \%$ & $100.3 \%$ & $75.6 \%$ & $106.6 \%$ & $122.1 \%$ & $95.4 \%$ \\
\hline Nebraska & $66.6 \%$ & $107.9 \%$ & $65.2 \%$ & $92.1 \%$ & $97.7 \%$ & $82.8 \%$ \\
\hline Nevada & $54.0 \%$ & $100.2 \%$ & $80.0 \%$ & $108.3 \%$ & $78.0 \%$ & $90.0 \%$ \\
\hline New Hampshire & $56.9 \%$ & $104.8 \%$ & $75.8 \%$ & $109.4 \%$ & $143.7 \%$ & $107.5 \%$ \\
\hline sNew Jersey & $61.4 \%$ & $101.8 \%$ & $62.5 \%$ & $40.8 \%$ & $122.1 \%$ & $100.1 \%$ \\
\hline New Mexico & $47.8 \%$ & $82.6 \%$ & $54.5 \%$ & $97.1 \%$ & $58.0 \%$ & $95.3 \%$ \\
\hline New York & $56.9 \%$ & $84.9 \%$ & $25.2 \%$ & $58.5 \%$ & $98.9 \%$ & $93.4 \%$ \\
\hline North Carolina & $56.1 \%$ & $92.1 \%$ & $85.1 \%$ & $73.4 \%$ & $100.5 \%$ & $98.6 \%$ \\
\hline North Dakota & $82.9 \%$ & $144.1 \%$ & $81.0 \%$ & $77.8 \%$ & $130.6 \%$ & $101.8 \%$ \\
\hline Ohio & $62.5 \%$ & $89.4 \%$ & $57.7 \%$ & $90.1 \%$ & $116.8 \%$ & $100.0 \%$ \\
\hline Oklahoma & $45.9 \%$ & $88.0 \%$ & $95.8 \%$ & $98.2 \%$ & $114.5 \%$ & $110.6 \%$ \\
\hline Oregon & $47.4 \%$ & $75.2 \%$ & $54.3 \%$ & $82.2 \%$ & $74.0 \%$ & $64.4 \%$ \\
\hline Pennsylvania & $55.4 \%$ & $93.3 \%$ & $50.1 \%$ & $83.3 \%$ & $85.0 \%$ & $92.5 \%$ \\
\hline
\end{tabular}




\begin{tabular}{lcc|cc|cc} 
Rhode Island & $54.5 \%$ & $77.8 \%$ & $57.7 \%$ & $80.0 \%$ & $102.3 \%$ & $96.7 \%$ \\
South Carolina & $51.9 \%$ & $78.3 \%$ & $116.2 \%$ & $100.2 \%$ & $87.3 \%$ & $96.3 \%$ \\
South Dakota & $67.8 \%$ & $100.0 \%$ & $84.8 \%$ & $123.0 \%$ & $78.0 \%$ & $91.5 \%$ \\
Tennessee & $53.5 \%$ & $74.6 \%$ & $136.2 \%$ & $103.7 \%$ & $79.7 \%$ & $89.8 \%$ \\
Texas & $54.6 \%$ & $93.0 \%$ & $144.6 \%$ & $102.5 \%$ & $81.3 \%$ & $88.2 \%$ \\
Utah & $64.3 \%$ & $100.7 \%$ & $71.2 \%$ & $58.5 \%$ & $94.2 \%$ & $101.1 \%$ \\
Vermont & $60.0 \%$ & $85.4 \%$ & $67.9 \%$ & $67.8 \%$ & $78.5 \%$ & $79.1 \%$ \\
Virginia & $44.4 \%$ & $80.9 \%$ & $81.0 \%$ & $84.7 \%$ & $75.4 \%$ & $91.0 \%$ \\
Washington & $51.2 \%$ & $92.7 \%$ & $33.6 \%$ & $97.5 \%$ & $83.9 \%$ & $78.1 \%$ \\
West Virginia & $60.6 \%$ & $90.8 \%$ & $50.9 \%$ & $96.7 \%$ & $102.5 \%$ & $103.5 \%$ \\
Wisconsin & $60.7 \%$ & $90.6 \%$ & $22.1 \%$ & $91.1 \%$ & $105.3 \%$ & $94.1 \%$ \\
Wyoming & $69.5 \%$ & $128.2 \%$ & $61.2 \%$ & $124.0 \%$ & $133.6 \%$ & $133.0 \%$ \\
US (2013-15) & $\mathbf{5 3 . 2 \%}$ & $\mathbf{8 7 . 4 \%}$ & $\mathbf{4 7 . 6 \%}$ & $\mathbf{8 2 . 1 \%}$ & $\mathbf{8 4 . 8 \%}$ & $\mathbf{9 1 . 1 \%}$ \\
Mean Difference & $43.9 \%$ & $12.1 \%$ & $40.6 \%$ & $18.1 \%$ & $17.1 \%$ & $10.8 \%$ \\
from 100\% & & & & & &
\end{tabular}

Note: Values refer to the share of benefits captured in the CPS (before and after TRIM3) relative to the sum of benefits allocated according to administrative records. The mean difference (final row) is calculated as the mean of the absolute values of states' percentagepoint distance from $100 \%$. For each of the three programs, the difference is smaller after the TRIM3 adjustments rather than before, indicating that the TRIM3 adjustments provide a more accurate measure of benefits for the average state.

Data Sources: SNAP: Administrative data on state-level benefit payments are provided on a monthly basis, which I sum to each calendar year for an estimate of annual spending. Source: U.S. Department of Agriculture, Food \& Nutrition Services.

TANF: State-level spending on Basic Assistance is provided annually. In most states, Basic Assistance refers to cash assistance. In some states, however, this may also entail a comparatively small set of payments for foster care maintenance payments or guardianship subsidies. Source: U.S. Department of Health \& Human Services, Administration on Children \& Families

SSI: Administrative records on state-level SSI payments are provided for the month of December in each calendar year. I multiply the December value by 12 to produce an estimate of annual spending. Source: U.S. Social Security Administration. 
Table A2: State-Level Estimates of Poverty Before \& After TRIM3 Adjustments (Three-Year Average, 2013 to 2015)

\begin{tabular}{|c|c|c|c|c|c|c|}
\hline & $\begin{array}{c}\text { SPM, } \\
\text { Pre-TRIM }\end{array}$ & $\begin{array}{c}\text { SPM, } \\
\text { Post-TRIM }\end{array}$ & $\begin{array}{c}\text { Confidence } \\
\text { Interval, } \\
+/-\end{array}$ & $\begin{array}{l}\text { 50\% Median, } \\
\text { Pre-TRIM3 }\end{array}$ & $\begin{array}{c}50 \% \\
\text { Median, } \\
\text { Post-TRIM3 }\end{array}$ & $\begin{array}{c}\text { Confidence } \\
\text { Interval, } \\
+/-\end{array}$ \\
\hline Alabama & $14.0 \%$ & $11.9 \%$ & $0.7 \%$ & $21.5 \%$ & $20.5 \%$ & $0.9 \%$ \\
\hline Alaska & $12.3 \%$ & $9.6 \%$ & $0.7 \%$ & $11.5 \%$ & $9.8 \%$ & $0.7 \%$ \\
\hline Arizona & $18.9 \%$ & $17.0 \%$ & $0.8 \%$ & $22.0 \%$ & $20.4 \%$ & $0.9 \%$ \\
\hline Arkansas & $14.1 \%$ & $12.5 \%$ & $0.7 \%$ & $22.3 \%$ & $21.6 \%$ & $0.9 \%$ \\
\hline California & $21.1 \%$ & $19.1 \%$ & $0.3 \%$ & $16.1 \%$ & $14.1 \%$ & $0.3 \%$ \\
\hline Colorado & $11.4 \%$ & $10.2 \%$ & $0.6 \%$ & $11.5 \%$ & $10.3 \%$ & $0.6 \%$ \\
\hline Connecticut & $11.7 \%$ & $10.7 \%$ & $0.7 \%$ & $9.5 \%$ & $8.7 \%$ & $0.6 \%$ \\
\hline Delaware & $11.8 \%$ & $10.5 \%$ & $0.7 \%$ & $13.5 \%$ & $12.5 \%$ & $0.8 \%$ \\
\hline Florida & $19.2 \%$ & $17.5 \%$ & $0.5 \%$ & $19.3 \%$ & $18.1 \%$ & $0.5 \%$ \\
\hline Georgia & $16.3 \%$ & $13.8 \%$ & $0.6 \%$ & $20.9 \%$ & $19.3 \%$ & $0.7 \%$ \\
\hline Hawaii & $16.5 \%$ & $13.4 \%$ & $0.7 \%$ & $10.2 \%$ & $8.0 \%$ & $0.6 \%$ \\
\hline Idaho & $10.2 \%$ & $8.8 \%$ & $0.7 \%$ & $13.9 \%$ & $12.7 \%$ & $0.8 \%$ \\
\hline Illinois & $13.8 \%$ & $12.3 \%$ & $0.5 \%$ & $14.6 \%$ & $13.3 \%$ & $0.5 \%$ \\
\hline Indiana & $12.0 \%$ & $11.0 \%$ & $0.7 \%$ & $16.3 \%$ & $15.0 \%$ & $0.8 \%$ \\
\hline Iowa & $8.8 \%$ & $7.5 \%$ & $0.6 \%$ & $12.6 \%$ & $11.0 \%$ & $0.7 \%$ \\
\hline Kansas & $10.8 \%$ & $9.4 \%$ & $0.7 \%$ & $14.8 \%$ & $13.6 \%$ & $0.8 \%$ \\
\hline Kentucky & $15.4 \%$ & $13.6 \%$ & $0.8 \%$ & $24.2 \%$ & $22.4 \%$ & $1.0 \%$ \\
\hline Louisiana & $18.5 \%$ & $16.6 \%$ & $0.7 \%$ & $25.4 \%$ & $24.2 \%$ & $0.8 \%$ \\
\hline Maine & $11.0 \%$ & $9.5 \%$ & $0.8 \%$ & $15.2 \%$ & $14.1 \%$ & $1.0 \%$ \\
\hline Maryland & $13.8 \%$ & $12.7 \%$ & $0.7 \%$ & $10.4 \%$ & $9.7 \%$ & $0.6 \%$ \\
\hline Massachusetts & $14.5 \%$ & $13.8 \%$ & $0.7 \%$ & $12.0 \%$ & $11.3 \%$ & $0.7 \%$ \\
\hline Michigan & $12.8 \%$ & $11.0 \%$ & $0.6 \%$ & $16.6 \%$ & $14.9 \%$ & $0.7 \%$ \\
\hline Minnesota & $9.4 \%$ & $8.7 \%$ & $0.6 \%$ & $9.5 \%$ & $8.8 \%$ & $0.6 \%$ \\
\hline Mississippi & $16.3 \%$ & $15.3 \%$ & $0.8 \%$ & $26.9 \%$ & $25.8 \%$ & $1.0 \%$ \\
\hline Missouri & $10.9 \%$ & $10.1 \%$ & $0.7 \%$ & $13.1 \%$ & $13.0 \%$ & $0.8 \%$ \\
\hline Montana & $11.1 \%$ & $9.8 \%$ & $0.7 \%$ & $15.1 \%$ & $14.1 \%$ & $0.8 \%$ \\
\hline Nebraska & $10.0 \%$ & $8.9 \%$ & $0.7 \%$ & $12.8 \%$ & $12.0 \%$ & $0.8 \%$ \\
\hline Nevada & $17.8 \%$ & $15.4 \%$ & $0.8 \%$ & $18.9 \%$ & $17.1 \%$ & $0.9 \%$ \\
\hline New Hampshire & $9.8 \%$ & $9.3 \%$ & $0.7 \%$ & $8.6 \%$ & $7.6 \%$ & $0.6 \%$ \\
\hline New Jersey & $15.9 \%$ & $14.8 \%$ & $0.7 \%$ & $12.1 \%$ & $11.1 \%$ & $0.6 \%$ \\
\hline New Mexico & $15.3 \%$ & $13.6 \%$ & $0.7 \%$ & $21.5 \%$ & $19.9 \%$ & $0.8 \%$ \\
\hline New York & $16.7 \%$ & $15.0 \%$ & $0.5 \%$ & $14.7 \%$ & $13.5 \%$ & $0.5 \%$ \\
\hline North Carolina & $14.7 \%$ & $13.0 \%$ & $0.6 \%$ & $20.3 \%$ & $19.5 \%$ & $0.7 \%$ \\
\hline North Dakota & $9.7 \%$ & $8.7 \%$ & $0.7 \%$ & $11.8 \%$ & $10.7 \%$ & $0.8 \%$ \\
\hline Ohio & $11.6 \%$ & $10.5 \%$ & $0.5 \%$ & $16.8 \%$ & $15.7 \%$ & $0.6 \%$ \\
\hline Oklahoma & $12.6 \%$ & $11.2 \%$ & $0.7 \%$ & $19.2 \%$ & $17.8 \%$ & $0.9 \%$ \\
\hline Oregon & $13.7 \%$ & $12.1 \%$ & $0.7 \%$ & $14.4 \%$ & $13.0 \%$ & $0.8 \%$ \\
\hline Pennsylvania & $11.8 \%$ & $10.5 \%$ & $0.5 \%$ & $14.9 \%$ & $13.5 \%$ & $0.6 \%$ \\
\hline Rhode Island & $12.2 \%$ & $11.1 \%$ & $0.8 \%$ & $13.4 \%$ & $12.8 \%$ & $0.9 \%$ \\
\hline South Carolina & $15.2 \%$ & $13.2 \%$ & $0.8 \%$ & $20.2 \%$ & $19.4 \%$ & $0.9 \%$ \\
\hline South Dakota & $9.6 \%$ & $8.3 \%$ & $0.7 \%$ & $14.1 \%$ & $13.4 \%$ & $0.9 \%$ \\
\hline Tennessee & $15.2 \%$ & $13.7 \%$ & $0.8 \%$ & $20.7 \%$ & $19.6 \%$ & $0.9 \%$ \\
\hline Texas & $14.7 \%$ & $13.2 \%$ & $0.4 \%$ & $18.3 \%$ & $16.8 \%$ & $0.4 \%$ \\
\hline Utah & $9.4 \%$ & $8.8 \%$ & $0.6 \%$ & $11.1 \%$ & $10.2 \%$ & $0.7 \%$ \\
\hline Vermont & $8.6 \%$ & $8.1 \%$ & $0.7 \%$ & $10.6 \%$ & $9.7 \%$ & $0.8 \%$ \\
\hline Virginia & $13.9 \%$ & $12.7 \%$ & $0.6 \%$ & $12.4 \%$ & $11.5 \%$ & $0.6 \%$ \\
\hline Washington & $12.1 \%$ & $10.3 \%$ & $0.6 \%$ & $11.8 \%$ & $10.7 \%$ & $0.6 \%$ \\
\hline West Virginia & $12.9 \%$ & $11.1 \%$ & $0.7 \%$ & $22.8 \%$ & $22.4 \%$ & $0.9 \%$ \\
\hline Wisconsin & $10.8 \%$ & $9.0 \%$ & $0.6 \%$ & $12.3 \%$ & $11.2 \%$ & $0.7 \%$ \\
\hline Wyoming & $9.4 \%$ & $8.3 \%$ & $0.7 \%$ & $11.5 \%$ & $10.9 \%$ & $0.8 \%$ \\
\hline
\end{tabular}

Note: Bolded cells indicate lack of statistically significant difference between pre- and post-TRIM3 estimates at 95 percent confidence levels. 


\section{CPS ASEC CPS ASEC Absolute \\ Before TRIM3 After TRIM3 Change}

\begin{tabular}{llccc}
\hline SNAP & & & & \\
Households with & Median Value & $\$ 3,288$ & $\$ 3,366$ & $\$ 78$ \\
Children & Coverage Rate & $17.9 \%$ & $28.8 \%$ & $10.9 \%^{*}$ \\
Households & Median Value & $\$ 1,344$ & $\$ 1,344$ & $\$ 0$ \\
without Children & Coverage Rate & $8.0 \%$ & $13.5 \%$ & $5.5 \% *$ \\
Total Population & Median Value & $\$ 2,160$ & $\$ 2,160$ & $\$ 0$ \\
& Coverage Rate & $11.1 \%$ & $18.3 \%$ & $7.2 \% *$ \\
\hline TANF & & & & \\
Households with & Median Value & $\$ 2,736$ & $\$ 3,048$ & $\$ 312$ \\
Children & Coverage Rate & $2.0 \%$ & $4.4 \%$ & $2.4 \% *$ \\
Households & Median Value & $\$ 3,600$ & $\$ 2,184$ & $-\$ 1,416$ \\
without Children & Coverage Rate & $0.2 \%$ & $0.1 \%$ & $-0.2 \%$ \\
Total Population & Median Value & $\$ 2,808$ & $\$ 3,048$ & $\$ 240$ \\
& Coverage Rate & $0.8 \%$ & $1.4 \%$ & $0.6 \% *$ \\
\hline SSI & & & & \\
Households with & Median Value & $\$ 8,772$ & $\$ 8,796$ & $\$ 24$ \\
Children & Coverage Rate & $3.5 \%$ & $6.0 \%$ & $2.5 \% *$ \\
Households & Median Value & $\$ 8,784$ & $\$ 8,796$ & $\$ 12$ \\
without Children & Coverage Rate & $4.8 \%$ & $5.5 \%$ & $0.7 \%$ \\
Total Population & Median Value & $\$ 8,784$ & $\$ 8,796$ & $\$ 12$ \\
& Coverage Rate & $4.4 \%$ & $5.7 \%$ & $1.3 \% *$ \\
\hline
\end{tabular}

Note: Median value refers to the median benefit among households receiving any positive value of the benefit in 2015. Coverage rate refers to the share of households receiving any positive value of the benefit in 2015. Asterisk (*) in Absolute Change column indicates change in coverage rates is statistically different from zero (95\% confidence). Thus, the difference in coverage rates for TANF and SSI among households without children is not statistically significant. Similarly, the large decline in the conditional median among households without children receiving TANF is of little consequence: the sample size of such households is tiny ( 29 households) and the difference in the conditional means (not displayed) is insignificant. 
APPENDIX III: Effect of Benefit Underreporting on Poverty Estimates by Program

\begin{tabular}{lcrrrr}
\hline & \multicolumn{5}{c}{ TRIM3 Adjustments only for: } \\
\hline & Unadjusted & \multicolumn{1}{c}{ SNAP } & \multicolumn{1}{c}{ TANF } & \multicolumn{1}{c}{ SSI } & \multicolumn{1}{c}{ All } \\
\hline SPM & $14.3 \%$ & $13.3 \%$ & $14.2 \%$ & $13.9 \%$ & $12.7 \%$ \\
Percentage-Point Change & - & -1.0 & -0.1 & -0.4 & -1.6 \\
Share of Pre-Post Difference & - & $63.2 \%$ & $8.0 \%$ & $25.8 \%$ & \multicolumn{1}{c}{-} \\
\hline $\mathbf{5 0 \%}$ Federal Median & $16.0 \%$ & $15.1 \%$ & $15.9 \%$ & $15.8 \%$ & $14.8 \%$ \\
Percentage-Point Change & - & -0.9 & -0.1 & -0.2 & -1.2 \\
Share of Pre-Post Difference & - & $74.2 \%$ & $8.2 \%$ & $18.4 \%$ & - \\
\hline
\end{tabular}

Note: 95 percent confidence intervals on poverty estimates: $+/-0.17 \%$. Differences in poverty estimates before and after TRIM3's TANF adjustments are not statistically significant. "All" column includes TRIM3 benefit adjustments for SNAP, TANF, and SSI. "Share of pre-post difference" indicates contribution of individual program relative to total change in poverty after adjusting for all three programs. 


\section{APPENDIX IV: Documentation for Applying Benefit Adjustments to U.S. Current Population Survey}

The documentation below provides guidance on adjusting for benefit underreporting in the CPS ASEC and for replicating the analyses in this paper. The replication packages contains five steps:
I. Accessing TRIM3
II. Accessing the CPS ASEC
III. Downloading TRIM3 Files
IV. Merging TRIM to the CPS ASEC
V. Re-Estimating Poverty Rates
a. Supplemental Poverty Measure
b. $50 \%$ of Median Income

\section{Accessing TRIM3}

Researchers can request access the Urban Institute's TRIM3 simulation model upon registration via online form. The link to register is: http://trim3.urban.org/Registration/. There is no charge to access the baseline data, but users must share their intended use of the TRIM3 data. Registration is necessary to download the TRIM3 data on imputed SNAP, TANF, and SSI benefit receipt.

More information on TRIM: http://trim3.urban.org

More information on the Urban Institute: http://urban.org

\section{Accessing the CPS ASEC}

There are multiple ways to access the Annual Social and Economic Supplement of the Current Population Survey (CPS ASEC, also referred to as the March CPS files). Two options include:

U.S. Census Bureau: https://thedataweb.rm.census.gov/ftp/cps_ftp.html

IPUMS CPS (after registration): https://cps.ipums.org/cps/

The replication package presented here uses the 2014 - 2016 CPS ASEC files (referring to reference years 2013 to 2015) from IPUMS CPS. Researchers using the Census files should be aware that some of the variable labels in the dofiles presented below may need to be converted from IPUMS to Census labeling schema (i.e. changing hseq to h_seq).

To compute Supplemental Poverty Measure (SPM) rates, I utilize historical SPM data from the Center on Poverty \& Social Policy at Columbia University. Researchers can access the public-use files after registering at https://www.povertycenter.columbia.edu/historical-spmdata-reg. Download the 2016 "Stata 12 DTA" file (CPS ASEC 2016 referring to reference year 2015) and save locally. The code provided in Dofile 2 (below) will merge the file into the CPS ASEC and allow for re-estimation of SPM poverty rates with TRIM-adjusted benefits. 


\section{Download TRIM3 Files}

After registering for and receiving access to TRIM3, you can then download the files needed to adjust for benefit underreporting in the CPS ASEC. To do so, visit the TRIM3 website (trim3.urban.org) and select the TRIM3 Navigator link using your login credentials. On the next page, select "Microdata" or "Microdata Examiner."

This paper uses the 2013 to 2015 microdata files, but TRIM3 files are available for the 1993 March CPS onward (if using the older files, however, take note that TRIM3 imputation procedures may have changed over time). Here, I detail how to download and merge the 2015 TRIM file into the CPS ASEC, but the same procedure applies for other years.

Select the 2015 (2016 CPS ASEC) input data set. You will then download, at a minimum, the following files, selecting the "extract data" link next to each. The sub-bullets below each file name indicate the variables within each extract that you should select prior to download:

- Alien2015 Person

- HOUSEHOLDID

- FAMILYID

- PERSONID

- CpsPersonID

- LineNumber

- PersonWeight

- Alien2015 Household

○ HOUSEHOLDID

○ AlienHouseholdSplit

○ HouseholdWeight

- HighIncomeClone

- OldIdentifier

- Alien2015 Family

○ HOUSEHOLDID

- FAMILYID

- CpsIdentifier

- SN2015

○ HOUSEHOLDID

- PERSONID

- ANNUALBENEFITSRECEIVED

- SSI2015

○ HOUSEHOLDID

- PERSONID

- ANNUALSSIBENEFITSRECEIVED

- TF2015

○ HOUSEHOLDID

- PERSONID

- ANNUALBENEFITSRECEIVED 
Under "formatting options", select Stata 2.1 format (if using Stata) and extract each set of data. Follow the link on the proceeding page to begin the download. Save each file into a local folder. If downloading files from multiple years, I recommend saving them into separate folders with the respective year as the folder title. Recommended file names for the 2015 downloads (useful if following the merge instructions in the dofiles below) are, respectively: input2015p, input2015h, input2015f, snap2015, ssi2015, tanf2015.

\section{Merging TRIM3 into CPS ASEC}

After downloading the TRIM3 files, you can now merge them into the CPS ASEC. This process consists of three steps: the first is to merge the separate TRIM3 files into one unified file. The second step is to merge the unified TRIM3 file into the CPS. The third step then treats the adjusted CPS ASEC file to account for the presence of high-income clones and alien replicates within the TRIM3 data.

Download the Stata dofile here to view and run the commands:

Dofile 1 of 2: Merging TRIM3 into CPS ASEC

Download: https://github.com/cpstotrim/dofiles/blob/master/replication_dofile1.do

\section{Re-Estimating Poverty Rates}

The Stata dofile below contains the code to estimate poverty rates with the TRIM3-adjusted benefits and to replicate each of the analyses in this paper.

Download the Stata dofile here to view and run the commands:

Dofile 2 of 2: Estimating Poverty Rates with TRIM3-Adjusted Benefits

Download: https://github.com/cpstotrim/dofiles/blob/master/replication_dofile2.do 